\title{
Título: Caracterização do dimorfismo intrassexual masculino de Doryteuthis plei (Mollusca: Cephalopoda) como base para compreensão dos mecanismos de competição espermática em lulas
}

\section{Resumo}

O processo de seleção sexual influencia de forma intensa o sucesso reprodutivo de cada indivíduo. Desde sua formulação teórica durante o século XIX, evidências cumulativas a respeito da poliandria em fêmeas permitiram a ampliação de seu conceito inicial, uma vez constatada que a disputa pela paternidade da prole não se limitava à competição pelo acesso à fêmea, mas poderia também prolongar-se mesmo após a cópula. Durante a década de 1970, essa disputa pós-copulatória entre machos foi formalizada sob o conceito de competição espermática, a qual visa a maximizar o sucesso do esperma de um macho sobre um rival na fertilização dos ovos. Evidências para um número crescente de táxons demonstram que a intensa competição pré e pós-copulatória entre machos é também uma das fontes responsáveis pela evolução e manutenção de táticas alternativas de reprodução dentro de uma mesma espécie, nas quais machos com menor sucesso na monopolização de fêmeas e combate com intraespecíficos adotam comportamentos furtivos para acesso ao sexo oposto, como forma de assegurar algum sucesso reprodutivo. Em muitas espécies, a adoção de táticas alternativas de reprodução são relacionadas não somente às diferenças comportamentais entre os machos, mas também à diversidade fenotípica dentro do mesmo sexo, caracterizada por descontinuidades morfológicas, fisiológicas e de ciclo de vida, conhecida pelo termo 'dimorfismo intrassexual'. Em lulas da família Loliginidae, a existência de morfos alternativos, denominados machos consort e sneaker, já foi constatada para diversas espécies e é associada a diferenças comportamentais entre eles, principalmente relacionadas à posição de cópula e sítio de deposição de espermatóforos no interior da fêmea. No entanto, a associação entre táticas alternativas de reprodução e dimorfismo intrassexual em machos é praticamente desconhecida, com exceção à espécie Heterololigo bleekeri, para a qual esse dimorfismo tem sido estudado extensivamente ao longo da última década. Nesse contexto, a presente Dissertação de Mestrado teve como principal objetivo investigar a existência de dimorfismo intrassexual masculino em Doryteuthis plei (Blainville, 1823), uma espécie de 
importância comercial para as regiões Sul e Sudeste do Brasil e para a qual, apesar de evidências indiretas sugerirem sua presença, tal dimorfismo nunca havia sido averiguado. Por meio de análises morfológicas e modelos estatísticos, o primeiro capítulo descreve a existência desse dimorfismo na espécie, o qual foi reconhecido a partir da constatação da presença de duas classes de tamanho de machos sexualmente maduros, caracterizadas pela produção de espermatóforos e espermatângios com morfologias descontínuas. Além disso, espermatângios amostrados de machos das duas classes de tamanho mostraram-se congruentes àquelas implantados nos dois sítios distintos da fêmea, resultado que permitiu associar o dimorfismo intrassexual à adoção das táticas de sneaker e consort na espécie. A partir dessa constatação, o primeiro capítulo explorou ainda o investimento gonadal exibido por machos dimórficos. Os resultados mostraram que machos sneakers apresentavam maiores investimentos relativos em gônadas do que machos consorts, um resultado que se enquadra nos modelos teóricos de "sneaks and guarders" de competição espermática. No entanto, enquanto as premissas teóricas propõem também que machos sneakers devem apresentar maiores investimentos por fêmea, constatamos que, na espécie de estudo, machos sneakers produzem espermatóforos com menor proporção de massa espermática do que machos consorts. Esses resultados, somados a observações comportamentais realizadas ao longo desse trabalho, sugerem que a estratégia adotada por machos sneakers deve estar relacionada ao fracionamento de seu investimento em produtos ejaculatórios, de forma que investimentos menores por fêmea permitiriam a realização de maior número de cópulas. Dando continuidade à caracterização do dimorfismo intrassexual na espécie, análises comparativas entre machos dimórficos com relação a estruturas do sistema reprodutor, tema do segundo capítulo, demonstraram que as diferenças quanto à morfologia funcional de espermatóforos intactos estavam associadas às divergências encontradas quanto à reação espermatofórica, liberação de espermatozoides e morfologia de espermatângios entre machos sneakers e consorts. Além disso, sob o contexto da competição espermática, o segundo capítulo discute como o padrão de reprodução de lulas da família Loliginidae, e.g., a existência de dois sítios de fertilização e diferenças nos intervalos entre cópulas e desovas, resultaria em pressões seletivas divergentes sobre os produtos ejaculatórios de machos dimórficos e influenciaria a evolução e manutenção do dimorfismo intrassexual na espécie. Por fim, o terceiro capítulo aborda a descoberta de machos com espermatóforos e espermatângios com morfologias intermediárias entre os fenótipos de sneakers e consorts, além da questão da diferença de idade entre machos dimórficos. Combinados, os resultados desse capítulo permitiram a proposição de uma hipótese ontogenética sobre a expressão de fenótipos alternativos na espécie, uma questão 
extremamente inovadora para cefalópodes. Apesar de tratar-se de um campo ainda completamente inexplorado para o grupo, espera-se que esses resultados contribuam para a compreensão dos fatores responsáveis pela expressão sequencial de fenótipos alternativos e pela determinação do dimorfismo intrassexual em lulas. 


\begin{abstract}
Sexual selection comprises a powerful force that intensively influences the reproductive success of each individual. Since its theoretical formulation in the nineteenth century, cumulative evidence regarding the existence of polyandry in females has expanded its initial concept, once it became clear that offspring paternity disputes were not limited to the competition for female access, but that they could in fact be prolonged even after copulation. In the 1970s, this male post-copulatory dispute was formalized under the concept of sperm competition, which aims at maximizing the success of one male's sperm over its competitors in the fertilization of females' eggs. Evidence gathered from a growing number of taxa has shown that intense pre and post-copulatory competition between males is also one of the responsible sources for the evolution and maintenance of alternative reproductive tactics within a species, in which males that are less successful in mate guarding and fighting contests with conspecifics adopt sneaking and opportunistic behaviors as a way to ensure some mating success. In many species, alternative mating tactics are not restricted to behavioral differences between males, being also related to a phenotypic diversity, with discontinuous morphological and physiological traits and distinct life histories between conspecifics, a phenomenon known as intrasexual dimorphism. In loliginid squids, the existence of alternative morphs (sneaker and consort males) has already been reported for several species, and it is has been correlated to behavioral differences, specially related to mating position and spermatophore deposition sites within the female's body. However, the association between alternative mating tactics and male intrasexual dimorphism is virtually unexplored, except for the species Heterololigo bleekeri, in which such dimorphism has been extensively studied over the last decade. In this context, the present Master's Dissertation aimed to investigate the existence of male intrasexual dimorphism in Doryteuthis plei (Blainville, 1823), a squid of commercial importance in southern and southeastern Brazil, and for which such dimorphism has never been investigated, although indirect evidence suggests its existence. Using morphological analyses and statistical models, the first chapter describes the presence of such dimorphism in the species, which was detected based on the identification of two body size classes of sexually mature males, characterized by spermatophores and spermatangia displaying discontinuous morphologies between each other. Moreover, spermatangia sampled from both body size classes were congruent with those implanted on distinct female sites, a result that allowed the association between intrassexual
\end{abstract}


dimorphism and adoption of sneaker and consort mating tactics in the species. Additionally, the first chapter also investigated the gonadal investment from dimorphic males, showing that sneakers exhibited higher investments in gonads than consorts, a result that fits into the theoretical 'sneaks and guards' models of sperm competition. However, while theoretical assumptions propose that sneakers should also present larger investments per female, we show that $D$. plei sneaker males produce spermatophores with lower concentrations of sperm mass than consorts. Combining these results with behavioral observations obtained throughout this study, we suggest that the sneaker strategy might be related to partitioning their ejaculate expenditure into extra mating opportunities, thus investing less per female but more in number of copulations. A further characterization of intrasexual dimorphism in this species was the main subject of the second chapter. Through comparative analyses of reproductive structures from dimorphic males, the results revealed that differences in the structural morphology of intact spermatophores were associated to differences regarding the spermatophoric reaction, spermatozoa release and spermatangia morphology between sneakers and consorts. Furthermore, under the context of sperm competition, the second chapter also provided a discussion on how the reproductive pattern of loliginid squids, e.g., the existence of two sites for fertilization of eggs and differences in the interval between mating and egg-laying, might result in divergent selective pressures on ejaculates from dimorphic males, influencing the evolution and maintenance of intrasexual dimorphism in this species. Finally, the third chapter describes the discovery of males that produced spermatophores and spermatangia displaying intermediate morphologies between both sneaker and consort phenotypes, and age differences reported for dimorphic males in the species. Combined, these results allowed the formulation of an ontogenetic hypothesis regarding alternative phenotype expression, which is extremely innovative for cephalopods. Although this hypothesis comprises a completely unexplored field for this group, it is highly expected that these results might contribute to the further understanding of possible factors that may be responsible for the sequential expression of alternative phenotypes, and ultimately for the determination of intrasexual dimorphism in squids. 


\section{Introdução}

\section{Seleção sexual}

O conceito formal de seleção sexual foi inicialmente estruturado durante o século XIX, quando Charles Darwin publicou o livro "The descent of man, and selection in relation to sex” em 1871 (Darwin, 1871). As questões centrais a respeito do tema surgiram a partir do acúmulo de observações relacionadas às diferenças, tanto morfológicas quanto comportamentais, exibidas por machos e fêmeas da mesma espécie. Um dos principais questionamentos de Darwin estava relacionado ao motivo pelo qual, de forma geral, indivíduos do sexo masculino apresentavam características fenotípicas exageradas em relação às fêmeas (e.g., Andersson, 1994; Andersson \& Iwasa, 1996; Kujiper et al., 2012). Caso esses atributos estivessem relacionados à aptidão e sobrevivência dos indivíduos, eles não deveriam estar limitados a somente um dos sexos, mas presentes em ambos e mantidos na população por meio da ação da seleção natural (Shuster \& Wade, 2003).

Baseado em suas observações, Darwin pressupôs que alguma forma de seleção deveria atuar de forma diferente sobre os dois sexos, afetando de forma mais intensa machos do que fêmeas, de forma que a exibição de características exageradas deveriam estar relacionadas ao sucesso reprodutivo desses indivíduos (e.g., Andersson, 1994, Møller, 1998). Dessa forma, a seleção sexual estaria relacionada à competição entre membros do mesmo sexo (i.e., entre machos) na disputa pelo acesso ao recurso limitado (i.e., as fêmeas), resultando no sucesso desigual entre indivíduos (Shuster et al., 2013). Como consequência, a seleção sexual deveria favorecer a evolução e manutenção de caracteres que elevem o sucesso reprodutivo dos indivíduos, mesmo que estes se mostrem custosos em termos de viabilidade e sobrevivência para aqueles que exibem tais caracteres (e.g., Lande, 1980; Manning, 1985; Andersson, 1994; Andersson \& Iwasa, 1996; Shuster \& Wade, 2003).

Segundo Darwin (1871), a seleção sexual poderia ocorrer através de mecanismos intersexuais e intrassexuais. O primeiro modo ocorre por meio da seleção criteriosa de parceiros sexuais, com base em uma série de características fenotípicas, incluindo, por exemplo, tamanho corporal, tamanho ou qualidade de armamentos ou ornamentos, quantidade ou qualidade de feromônios ou qualidade de exibições de cortejo (Trivers, 1972; Eberhard, 
1996). O segundo mecanismo ocorre por meio da competição entre indivíduos (geralmente machos) pelo acesso a indivíduos do sexo oposto (Andersson, 1994; Shuster \& Wade, 2003).

Por muitas décadas após a compreensão do papel da seleção sexual no contexto evolutivo, a ideia de que o sucesso reprodutivo dos machos estava somente atrelado ao número de cópulas bem sucedidas com o maior número de parceiras possíveis foi mantida (e.g., Bateman, 1948; Manning, 1985; Birkhead, 2010; Kvarnemo \& Simmons, 2013). Esse pensamento foi sustentado na ideia de que a competição entre machos teria como objetivo final o acesso à fêmea e a realização da cópula, a qual resultaria inevitavelmente na fertilização dos ovócitos da fềmea. Apesar de Darwin (1871) defender a escolha da fêmea como fator importante na seleção sexual, pouca atenção foi dada ao papel da fêmea nesse processo ao longo do século XIX (Trivers, 1972). As fêmeas eram vistas em sua vasta maioria como monogâmicas e defendia-se a ideia de que o sucesso dessas estaria relacionado ao número de embriões viáveis e à qualidade da prole gerada, o que não estaria relacionado ao número de cópulas efetuadas pela fêmea (e.g., Bateman, 1948; Thornhill \& Alcock, 1983; Manning, 1985; Birkhead \& Møller, 1998; Birkhead, 2010).

A participação efetiva das fêmeas no contexto da seleção sexual e no sucesso reprodutivo dos machos só foi reconhecida a partir da década de 1970 (Birkhead \& Pizzari, 2002; Shuster \& Wade, 2003; Birkhead, 2010). Ao contrário da concepção de que o sucesso reprodutivo das fêmeas seria indiferente ao número de cópulas realizadas, houve acúmulo expressivo de observações de cópulas múltiplas realizadas pelas fêmeas em diversos táxons, fenômeno denominado poliandria (e.g., Emlen \& Oring, 1977; Birkhead, 2010). Evidências relacionadas à poliandria mostram que a prática de cópulas com múltiplos parceiros traz benefícios indiretos à progênie, tais como aumento da viabilidade, diversidade e resistência, e ganhos diretos à fêmea, tais como aumento da fertilidade, reabastecimento do estoque de esperma, ganho de nutrientes, proteção em territórios, cuidado parental e redução do assédio de outros machos (Andersson \& Iwasa, 1996; Stockley, 1997; Birkhead \& Møller, 1998; Petrie \& Kempenaers, 1998; Zeh \& Zeh, 2001; Birkhead \& Pizzari, 2002; Andersson \& Simmons, 2006; Kuijper et al., 2012; Kvarnemo \& Simmons, 2013; Shuster et al., 2013; Forstmeier et al., 2014).

A constatação da existência da poliandria, associada à presença de órgãos especializados em armazenamento de esperma nas fêmeas de um número crescente de espécies, trouxe consequências drásticas para o conhecimento sobre seleção sexual (Birkhead 
\& Pizzari, 2002; Wigby \& Chapman, 2004; Parker \& Pizzari, 2010; Kvarnemo \& Simmons, 2013). O sucesso reprodutivo dos machos não estaria mais somente atrelado ao número de cópulas bem sucedidas, mas continuaria mesmo após a cópula e estaria relacionado ao número de fertilizações obtidas (Parker, 1984; Shuster, 2009). Com esses avanços, novos mecanismos que regem o sucesso reprodutivo de cada indivíduo na disputa pela paternidade da progênie começaram a ser elucidados, tais como a (1) competição pós-copulatória entre machos, conhecida como competição espermática e (2) a escolha críptica da fêmea (Shuster et al., 2013).

O termo 'escolha críptica da fêmea', descrito por Thornhill \& Alcock (1983), engloba toda a participação da fêmea - antes negligenciada - nos processos pós-copulatórios que podem levar à fertilização dos ovócitos. Os mecanismos de seleção críptica da fêmea podem envolver aspectos comportamentais, morfológicos e fisiológicos e vão desde o controle da ovulação até o transporte de espermatozoides, entre outros (Eberhard, 1996). Todos esses mecanismos têm efeitos fundamentais na competição pós-copulatória entre machos e na determinação de seu sucesso reprodutivo, uma vez que determinam o esperma de quais machos será armazenado e/ou utilizado para fertilizar os ovócitos (Birkhead \& Pizzari, 2002; Andersson \& Simmons, 2006). O termo “críptico" justifica-se por esses processos ocorrerem geralmente no interior do sistema reprodutor da fêmea, sendo de difícil observação (Birkhead \& Pizzari, 2002).

\subsection{Competição espermática}

A competição intrassexual entre machos esteve por muito tempo associada somente a adaptações, comportamentais ou morfológicas, relacionadas ao acesso e monopolização das fêmeas (Parker, 1984). Essa forma de competição esteve aliada à presença de armamentos utilizados em combates físicos entre indivíduos ou na elaboração de ornamentações e exibições de cortejo. Porém, a evidenciação de que fêmeas de muitas espécies realizam múltiplas cópulas durante o mesmo período reprodutivo revelou que a competição intrassexual não está limitada às adaptações que permitem aos machos efetuar cópulas com o maior número possível de fêmeas; a competição intrassexual pode ocorrer mesmo após a cópula por meio da competição espermática (Birkhead \& Pizzari, 2002; Wigby \& Chapman, 2004; Birkhead, 2010; Kvarnemo \& Simmons, 2013; Shuster et al., 2013). Esse termo foi 
proposto por Parker (1970), o qual define a competição espermática como a disputa entre o esperma de dois ou mais machos pela fertilização de um conjunto de ovócitos (Parker, 1970, 1998).

No contexto da competição espermática, machos de muitas espécies podem exibir adaptações relacionadas à maximização do sucesso de seu próprio esperma em relação a um macho rival (Parker, 1984, 1998; Simmons, 2001, 2014; Taborsky, 1998). A competição espermática pode ser minimizada por meio de adaptações exibidas pelos machos, relacionadas ao impedimento de acesso à fêmea ou seu trato reprodutor (Parker, 1970, 1984; Thornill \& Alcock, 1983; Eberhard, 1985; Birkhead \& Hunter, 1990; Stockley, 1997; Birkhead \& Møller, 1998; Simmons, 2001; Birkhead \& Pizzari, 2002; Wigby \& Chapman, 2004; Birkhead, 2010; Parker \& Pizzari, 2010; Kvarnemo \& Simmons, 2013). Essas adaptações podem incluir aspectos comportamentais, tais como prolongamento do tempo de cópula ou guarda da fêmea após a cópula (Parker, 1974; Yamamura \& Tsuji, 1989; Alcock, 1994; Fryer et al., 1999); fisiológicos, relacionados a barreiras bioquímicas, e.g., transferência de substâncias que reduzem ou inibem a receptividade da fêmea para novas cópulas (Cook \& Wedell, 1999; Andersson et al., 2000, 2004; Wigby \& Chapman, 2005); e morfológicos, via produção de barreiras físicas que impeçam a fêmea de copular novamente, tais como plugues seminais (mating plugs) (Matsumoto \& Suzuki, 1992), ou através de mecanismos que levam à remoção, destruição ou inativação do esperma de outros machos rivais (Parker et al., 1990; Helversen \& Helversen, 1991).

Além de adaptações para reduzir ou prevenir a competição espermática, há casos em que a competição não pode ser evitada. Nesse contexto, a seleção deve favorecer adaptações, principalmente relacionadas aos produtos ejaculatórios, que forneçam alguma vantagem aos machos na competição pela fertilização dos ovócitos da fêmea (Simmons, 2014). Considerando-se que há um limite quanto ao investimento energético em reprodução, deve existir um trade-off entre os custos associados à aquisição de parceiras (i.e., competição précopulatória) e à elaboração de produtos ejaculatórios (i.e., competição pós-copulatória ou espermática) (Parker, 1974, 1990a, 1990b; Ball \& Parker, 1997; Stockley, 1997; Taborsky, 1998; Simmons et al., 2007; Parker \& Pizzari, 2010; Simmons, 2014). Enquanto o primeiro gasto estabelece o número de cópulas possíveis que um macho pode obter, o segundo estabelece os ganhos obtidos por cópula, i.e., na competição espermática (Parker et al., 2013). Sob essa lógica, alocar recursos para produtos ejaculatórios aumenta o ganho por cópula, mas 
reduz o número de cópulas que um macho pode obter (Parker, 1990a; Birkhead \& Møller, 1998; Wedell et al., 2002).

O comportamento individual dos machos quanto à alocação de recursos para produtos ejaculatórios (e.g., tamanho do testículo, número ou tamanho dos espermatozoides) ou número de cópulas está relacionado à magnitude de competição espermática enfrentada (Parker et al., 1990; Ball \& Parker, 1996, 1997; Parker et al., 1996, 1997; Wedell et al., 2002; Parker \& Ball, 2005; Parker \& Pizzari, 2010). Os modelos teóricos de competição espermática entre espécies e dentro da mesma espécie baseiam-se em dois conceitos fundamentais: risco e intensidade de competição espermática. $\mathrm{O}$ primeiro corresponde à probabilidade da fêmea copular com mais de um macho durante o período reprodutivo, enquanto que o segundo corresponde ao número de machos competindo pela fêmea. Quando não há competição espermática, o macho deve alocar o mínimo de produtos ejaculatórios para determinada fêmea, somente o suficiente para garantir a fecundação (Parker, 1990a, 1990b; Parker et al., 1996, 1997; Parker, 1998).

No entanto, os modelos são diferentes quando os níveis de competição espermática são comparados entre duas ou mais espécies e dentro da mesma espécie. Entre espécies, os modelos predizem que o investimento masculino em produtos ejaculatórios deva ser diretamente proporcional ao aumento do risco e da intensidade de competição espermática (e.g., Møller, 1988a, 1989; Stockley \& Purvis, 1993; Gage, 1994; Hosken, 1997; Stockley et al., 1997; Pitcher et al., 2005; Lupold et al., 2008; delBarco-Trillo, 2011; Kelly \& Jennions, 2011; Montoto et al., 2011). Em outras palavras, quando espécies com diferentes riscos e/ou intensidades de competição espermática são comparadas entre si, machos da(s) espécie(s) que apresenta(m) maiores níveis de competição devem apresentar maiores investimentos em reprodução do que aqueles da(s) espécie(s) com menores riscos ou intensidade de competição espermática. No entanto, dentro de uma mesma espécie, o cenário é diferente. Em níveis pequenos de competição espermática, quando a fêmea pode ou não copular com outro macho, prevê-se que o macho aumente a alocação de recursos para produtos ejaculatórios por fêmea conforme o risco de competição espermática aumenta. Quando os níveis de competição espermática aumentam, de forma que a fêmea sempre copula com no mínimo dois machos, o modelo prevê que determinado macho deva reduzir seus gastos com produtos ejaculatórios por cópula conforme a intensidade de competição aumenta (e.g., Parker et al., 1996, 1997; Ball \& Parker, 1997; Birkhead \& Møller, 1998; Simmons et al., 1999; Wedell \& Cook, 1999; Alonzo \& Warner, 2000; Hosken \& Ward, 2001; Hosken et al., 2001; Pitnick et al., 2001; 
Stockley \& Seal, 2001; Martin \& Hosken, 2001; Wedell et al., 2002; García-González \& Gomendio, 2004; Thomas \& Simmons, 2007; Simmons \& García-González, 2008; Parker \& Pizzari, 2010).

Correlações positivas entre risco de competição espermática e tamanho relativo do testículo são encontradas em várias espécies de vertebrados e invertebrados, corroborando as predições dos modelos teóricos (Parker, 1993; Gage, 1994; Møller \& Briskie, 1995; Parker et al., 1996; Hosken, 1997; Stockley et al., 1997; Møller, 1998a, 1998b, 1989; Morrow \& Gage, 2000; Hosken \& Ward, 2001; Hosken et al., 2001; Pitnick et al., 2001; Wedell et al., 2002; Gage \& Freckleton, 2003; Pitcher et al., 2005; Lupold et al., 2008; Simmons \& GarcíaGonzález, 2008). Além disso, podem existir diferenças intraespecíficas quanto ao investimento gonadal. Em espécies nas quais machos dimórficos (i.e., associados a táticas alternativas de reprodução; ver item 1.2) coexistem na mesma população, indivíduos de tamanho menor, os quais em geral apresentam desvantagem no acesso à fêmea e portanto maior risco de competição espermática, tendem a apresentar maior investimento em produtos ejaculatórios e testículos relativamente maiores do que machos maiores e dominantes (Parker, 1990a, 1990b; Parker et al., 1996, 1997).

O investimento em produção espermática pode estar relacionado ao volume de espermatozoides inseminados por cópula ou a atributos relacionados à morfologia, mobilidade ou longevidade do espermatozoide (Taborsky, 1998; Wigby \& Chapman, 2004; Snook, 2005). Os modelos teóricos relacionados à competição espermática predizem que deva existir um trade-off entre o investimento nos diferentes atributos do espermatozoide, o investimento de determinado indivíduo dependendo da combinação de atributos que for mais vantajosa na fertilização (Parker, 1993; Taborsky, 1998; Immler et al., 2011; Simmons, 2014). Como o sucesso de fertilização é amplamente relacionado ao número de espermatozoides transferidos para a fêmea, o indivíduo deveria alocar seu investimento para produção de maior número de espermatozoides, minimizando o tamanho dos gametas (Parker, 1982, 1990a, 1990b, 1993; Parker et al., 1996; Ball \& Parker, 1996). No entanto, as evidências são contrastantes. Enquanto algumas espécies aumentam quantitativamente a produção ou transferência de espermatozoides conforme o risco de competição espermática aumenta (peixes, Stockley et al., 1997; gastrópodes, Oppliger et al., 1998; insetos, Gage \& Barnard, 1996; Gage \& Morrow, 2003; García-González \& Gomendio, 2004; Ingleby et al., 2010), outras espécies apresentam aumento no tamanho do espermatozoide (mamíferos, Gomendio \& Roldan, 1991; aves, Briskie et al., 1997; Lupold et al., 2008; lepidópteros, Gage, 1994; Morrow \& Gage, 
2000; nemátodes, LaMunyon \& Ward, 1998, 1999). Espermatozoides maiores demandam mais energia e portanto devem apresentar menor tempo de sobrevivência (Ball \& Parker, 1996; Stockley et al., 1997), de forma que tamanhos maiores só devem ser vantajosos em condições muito restritas (Parker, 1993; Hosken et al., 2001). Por exemplo, tamanhos maiores podem estar relacionados à maior velocidade de natação (Gomendio \& Roldan, 1991; Taborsky, 1998), maior resistência à remoção ou diluição (Gage, 1994; Wigby \& Chapman, 2004) ou à morfologia interna do sistema reprodutor da fêmea (Briskie et al., 1997; Snook, 2005).

\subsection{Táticas alternativas de reprodução e dimorfismo intrassexual em machos}

A seleção sexual, além de influenciar o sucesso reprodutivo de cada indivíduo, é também uma das fontes responsáveis pelo dimorfismo sexual (Lande, 1980; Fairbairn, 1997), caracterizado por diferenças morfológicas entre indivíduos maduros dos dois sexos (Andersson, 1994). O dimorfismo sexual é comum em um vasto número de espécies, em diversos táxons, sendo que na maioria deles as fêmeas são maiores que os machos (Darwin, 1871; Andersson, 1994; Fairbairn, 1997). Machos de grande tamanho, assim como diferenças de ornamentação ou armamento entre os dois sexos, têm sido associados aos processos de seleção sexual, principalmente àqueles relacionados à competição intrassexual entre machos pelo acesso às fêmeas (Lande, 1980; Emlen \& Nijhout, 2000; Shuster \& Wade, 2003; Blanckenhorn, 2005).

Nas espécies em que a poligamia é comum, i.e., machos e fêmeas copulam mais do que uma única vez e com mais do que um parceiro durante uma estação reprodutiva, há uma grande variância no sucesso reprodutivo dos indivíduos e a seleção sexual atua de forma intensa (Gadgil, 1972). Em geral, os custos associados à produção e manutenção de caracteres utilizados em exibições de corte, combates, proteção à fêmea e cuidado parental são elevados e nem todos os machos são capazes de sustentar altos investimentos para garantir seu sucesso reprodutivo (Simmons \& Tomkins, 1996; Buzatto et al., 2014). Nestas circunstâncias, indivíduos machos que apresentam desvantagem em relação à forte competição com seus coespecíficos e que apresentam menor sucesso na obtenção de cópulas podem optar por suprimir estes altos custos. Ao invés disso, esses indivíduos alocam seus recursos na exibição de táticas alternativas de reprodução que os permitam obter algum tipo de sucesso na 
competição reprodutiva (Dominey, 1980, 1984; Eberhard, 1982; Taborsky, 1998; Blackenhorn, 2005; Oliveira et al., 2008; Buzatto et al., 2014). Eventos de seleção disruptiva ${ }^{1}$ podem selecionar machos que pagam os altos custos e aqueles que conseguem contornar esse custo e mesmo assim obter fertilização (Gross, 1985; Hunt \& Simmons, 2000; Buzatto et al., 2014). Isso pode resultar não somente na descontinuidade comportamental, mas também de traços morfológicos, fisiológicos e de ciclo de vida entre indivíduos do mesmo sexo (geralmente machos) - fenômeno denominado dimorfismo intrassexual (Gadgil, 1972; Austad, 1984; Eberhard \& Gutierrez, 1991; Andersson, 1994; Gross, 1996; Taborsky et al., 2008; Smallegange \& Johansson, 2014).

O dimorfismo intrassexual masculino, associado a táticas alternativas de reprodução, é encontrado em diversos grupos de invertebrados e vertebrados (revisado em Taborsky et al., 2008) e é manifestado na forma de diversidade fenotípica caracterizada principalmente por dimorfismo em tamanho, com machos grandes (conhecidos como consorts, majors ou territoriais) e pequenos (conhecidos como sneakers, minors, satélites ou parasitas) (Dominey, 1980; Gross, 1996; Taborsky et al., 2008; Smallegange \& Johansson, 2014). De forma geral, os machos maiores possuem estruturas para competição física pela posse e monopolização de recursos e parceiras e adotam táticas dominantes, enquanto os machos menores são desprovidos de armamentos e adotam estratégias furtivas para acessar as fêmeas (Gross, 1996; Shuster \& Wade, 2003; Taborsky et al., 2008; Shashar \& Hanlon, 2013; Smallegange \& Johansson, 2014).

A expressão de fenótipos alternativos pode ser regulada por mecanismos genéticos, ambientais ou pela interação de ambos (Austad, 1984; Gross, 1996; Hazel et al., 1990; Taborsky, 1998; Brockmann, 2001; Shuster \& Wade, 2003). Evidências relacionadas à adoção de táticas baseada em diferenças genotípicas entre os indivíduos são relativamente raras, mas já foram documentadas para vertebrados (e.g., peixes, Dominey, 1980; Ryan et al., 1992; aves, Lank et al., 1995; lagartos, Sinervo \& Lively, 1996) e invertebrados (e.g., isópodes, Shuster \& Wade, 1991; ácaros, Radwan, 1995, 2003).

As táticas alternativas de reprodução podem ser flexíveis ou fixas ao longo da vida do indivíduo (Dominey, 1980; Austad, 1984; Gross, 1996; Taborsky, 1998; Taborsky et al., 2008). As táticas fixas, as quais podem ser determinadas por diferenças genotípicas entre os

\footnotetext{
${ }^{1}$ A seleção natural disruptiva ocorre quando simultanemente indivíduos de ambos os extremos da distribuição de determinado caráter (e.g., tamanho corporal) são favorecidos (i.e., apresentam maior aptidão) em relação a
} 
indivíduos ou podem estar relacionadas a aspectos ambientais ou do próprio indivíduo, são irreversíveis e não variam ao longo da vida dos machos (Dominey, 1980, 1984; Shuster \& Wade, 2003). As táticas flexíveis, por outro lado, são aquelas nas quais os indivíduos podem mudar de um comportamento para outro ao longo do desenvolvimento ou dependendo das condições ambientais. Nesse caso, a alternância entre estratégias pode ser simultânea, quando o indivíduo é capaz de mudar sua estratégia a qualquer momento, ou sequencial, quando a alteração está relacionada às mudanças ontogenéticas do próprio indivíduo (táticas simultâneas: peixes, Taborsky, 1994; anuros, Halliday \& Tejedo, 1995; aves, Westneat \& Stewart, 2003; crustáceos, Correa et al., 2003; táticas sequenciais: peixes, Alonzo et al., 2000).

A maioria dos casos documentados de táticas alternativas, sejam elas flexíveis ou fixas, apresenta expressão condicional (Dominey, 1984; Hazel et al., 1990; Gross, 1996; Hunt \& Simmons, 2001). A expressão de determinado fenótipo depende de condições intrínsecas do próprio animal (e.g., idade, tamanho, condição nutricional) ou extrínsecas (e.g., condições físicas ou sociais do ambiente). Um dos principais modelos referentes à adoção condicional de determinada tática pelos machos é denominado "modelo status-dependente", o qual parte das premissas de que o indivíduo é capaz de acessar as condições locais e tomar decisões sobre a melhor tática a ser adotada para proporcionar-lhe maior sucesso, dado seu status (i.e., aptidão do indivíduo em relação a outros competidores) (Hazel et al., 1990; Repka \& Gross, 1995; Gross, 1996; Gross \& Repka, 1998; Hunt \& Simmons, 2000; Tomkins \& Hazel, 2007). O modelo está relacionado à existência de um limiar a partir do qual a escolha da tática seria definida: se o indivíduo ultrapassa determinado valor, é mais vantajoso que ele adote uma tática dominante, enquanto que aqueles que não o ultrapassam podem ter maior sucesso se adotarem táticas furtivas (Hazel et al., 1990; Repka \& Gross, 1995; Gross, 1996; Roff, 1996; Gross \& Repka, 1998; Tomkins et al., 2004; Tomkins \& Hazel, 2007; Roff, 2011). Em geral, a adoção de uma tática ou outra depende do indivíduo atingir um limiar de tamanho corporal (e.g., salmão, Gross, 1991; Baum et al., 2004; Aubin-Horth et al., 2006; insetos, Emlen \& Nijhout, 2000; Hunt \& Simmons, 2001).

Em insetos, relativamente mais bem estudados sobre o tema, cerca de $95 \%$ das táticas alternativas de reprodução correspondem a estratégias condicionais (Buzatto et al., 2014). Em insetos, assim como outros artrópodes, a adoção de táticas tende a ser fixa ao longo da vida e está principalmente relacionada ao estado nutricional durante o desenvolvimento ontogenético (Dominey, 1984). Somente indivíduos com melhor condição nutricional durante o estágio 
larval apresentam maior crescimento e são capazes de ultrapassar o limiar de tamanho necessário para desenvolver-se no morfotipo dominante (e.g., insetos, Eberhard, 1982; Emlen \& Nijhout, 2000; Hunt \& Simmons, 2000; Moczek et al., 2002; Moczek \& Nijhout, 2003; ácaros, Radwan, 1995). Em outros grupos - principalmente nos quais há crescimento indeterminado ao longo da vida -, a adoção de táticas pode ser flexível e estar associada, por exemplo, à idade e tamanho: indivíduos mais jovens e menores adotam táticas furtivas; no entanto, ao longo da vida, estes podem ultrapassar o limiar de tamanho e, quando mais velhos, adotar táticas dominantes (Mazzoldi et al., 2000).

A adoção de táticas alternativas de reprodução entre os machos promove assimetria na competição espermática e diferenças no sucesso reprodutivo de cada morfotipo (Gage et al., 1995; Taborsky, 1998). Segundo os modelos teóricos de competição espermática, machos que adotam táticas furtivas estão sempre sujeitos a maior risco de competição espermática, uma vez que copulam com fêmeas que já copularam ou irão copular pelo menos uma vez com o macho dominante. Machos dominantes, no entanto, estão sujeitos à competição com menor frequência, dependendo da densidade de sneakers na população (Parker, 1990b; Wedell et al., 2002; Parker et al., 2013). Essa assimetria nas pressões seletivas pode impulsionar adaptações nas características ejaculatórias relacionadas a cada comportamento reprodutivo. Segundo modelos teóricos, machos sneaker devem investir mais em produção espermática que machos dominantes (Parker, 1990a, 1990b, 1993; Taborsky, 1998), algo que já foi constatado para diversas espécies com relação ao tamanho do testículo e/ou número de espermatozoides liberados (e.g., Dominey, 1980; Stockley \& Purvis, 1993; Taborsky, 1994; Gage et al., 1995; Simmons et al., 1999, 2007; Alonzo \& Warner, 2000; Tomkins \& Simmons, 2000; Stockley \& Seal, 2001; Hellriegel \& Blackenhorn, 2002; Wedell et al., 2002; Blackenhorn, 2005; Rudolfsen et al., 2006; Simmons \& García-González, 2008).

\section{Cefalópodes}

Os cefalópodes compreendem uma classe bem definida do filo Mollusca, com cerca de 800 espécies viventes. Seus representantes mais conhecidos são as lulas, polvos, sépias, lulas-vampiro e náutilos. Os registros fósseis indicam que os cefalópodes surgiram há cerca de 505 milhões de anos, durante o Cambriano Superior (Young et al., 1998). São animais 
exclusivamente marinhos, predadores ativos e possuem os sistemas nervoso e sensorial altamente desenvolvidos (Hanlon \& Messenger, 1996).

A morfologia típica de uma lula compreende uma cabeça bem desenvolvida, corpo cilíndrico e alongado, constituído pelo manto muscular e pela ampla cavidade do manto, a qual abriga os órgãos internos, e pelas nadadeiras localizadas na região lateroposterior do manto. Na extremidade anterior da cabeça há dez apêndices circum-orais e móveis, os quais são equipados com séries de ventosas e/ou ganchos que podem se distribuir por toda sua extensão. Dentre os apêndices, oito deles constituem os braços e dois apresentam-se mais alongados e são denominados tentáculos. No interior da região bucal está localizada a rádula, estrutura típica dos demais moluscos, composta por dentes quitinosos, e o bico, composto por um par de mandíbulas quitinosas (Jereb \& Roper, 2010).

\subsection{Classificação}

A Classe Cephalopoda é dividida em duas subclasses: Nautiloidea e Coleoidea. A subclasse Nautiloidea compreende somente a família Nautilidae, a qual apresenta apenas os gêneros Nautilus e Allonautilus com representantes viventes (Jereb \& Roper, 2010). O grupo é caracterizado pela presença de uma concha calcária externa; além disso, cromatóforos, lentes nos olhos e glândula da tinta estão ausentes (Hanlon \& Messenger, 1996). A subclasse Coleoidea, na qual está inserida a vasta maioria dos cefalópodes viventes, apresenta como característica principal a internalização e redução (ou até mesmo perda total) da concha ancestral (Strugnell et al., 2005), além da presença de cromatóforos, lentes e glândula da tinta (Hanlon \& Messenger, 1996). Em lulas, a concha é quitinosa e reduzida na forma de uma estrutura rígida de sustentação, conhecida como gládio ou pena (Boyle \& Rodhouse, 2005).

Os membros da subclasse Coleoidea são tradicionalmente subdivididos nas Superordens Decapodiformes e Octopodiformes, caracterizados pela presença de 10 e 8 apêndices circum-orais, respectivamente. Os Octopodiformes incluem as Ordens Vampyromorpha - na qual está inserida a lula-vampiro (Vampyroteuthis infernalis) - e Octopoda - a qual inclui os polvos e argonautas (Strugnell et al., 2005). De acordo com a classificação tradicional, os Decapodiformes eram subdivididos nas ordens Sepioidea - na qual estavam inseridas as sépias, sepiolídeos e espírulas - e Teuthoidea - a qual incluía as lulas, divididas nas subordens Myopsida e Oegopsida (Boyle, 1990; Young et al., 1998; 
Strugnell et al., 2005). Essas subordens apresentam como principal característica distintiva a membrana córnea que reveste o olho, estrutura presente em Myopsida mas ausente em Oegopsida (Jereb \& Roper, 2010). No entanto, classificações recentes, embasadas em dados morfológicos e moleculares, reconhecem sete ordens de Decapodiformes: Spirulida, Sepiida, Sepiolida, Idiosepiida, Bathyteuthida, Myopsida e Oegopsida (Alcock et al., 2015).

A espécie-modelo deste trabalho, Doryteuthis plei (Blainville, 1823), está inserida na família Loliginidae (ordem Myopsida). Seus representantes apresentam porte médio, com tamanhos máximos de $370 \mathrm{~mm}$ em machos e $260 \mathrm{~mm}$ em fêmeas (Jereb \& Roper, 2010). A espécie distribui-se ao longo da costa oeste do Oceano Atlântico, com registros desde a região centro-sul dos Estados Unidos até o norte da Argentina, sendo comumente encontrada na região de plataforma continental, desde a superfície até profundidades de 370 metros (Jereb \& Roper, 2010). Como é comum para várias espécies de lulas, os indivíduos permanecem associados ao fundo ao longo do dia, dispersando-se na coluna d'água durante a noite (Jereb \& Roper, 2010). Representantes sexualmente maduros são comumente encontrados ao longo de todo o ano, mas em geral ocorrem dois picos sazonais de reprodução; para as populações estudadas na região sul do Brasil, esses ocorrem ao longo dos meses de verão e de inverno (Perez et al., 2002). Estimativas de idade baseadas na análise de estatólitos revelam que a espécie apresenta ciclo de vida anual; para as populações distribuídas nas regiões sul e sudeste do Brasil, as estimativas sugerem ciclo de vida de aproximadamente oito a nove meses (Perez et al., 2006; Jereb \& Roper, 2010; Barcellos, 2014).

\subsection{Características gerais}

De forma geral, os cefalópodes apresentam altas taxas de crescimento, sendo capazes de atingir grandes tamanhos e maturidade sexual em um curto período de tempo, estimado entre seis e 24 meses dependendo da espécie (Boyle \& Rodhouse, 2005). O desenvolvimento embrionário dos cefalópodes ocorre de forma direta e apresenta duração variada, podendo prolongar-se desde alguns dias a muitos meses, dependendo principalmente da espécie e das condições do ambiente, tais como a temperatura. Em cefalópodes, não ocorre metamorfose previamente à fase adulta, de forma que é recorrente a utilização do termo paralarva para designar os estágios iniciais pós-eclosão. As paralarvas passam por mudanças graduais, tanto morfológicas quanto ecológicas, até atingirem a fase adulta (Jereb \& Roper, 2010). 
A vasta maioria dos cefalópodes apresenta tempo de vida curto, de cerca de seis meses a dois anos (Boyle \& Rodhouse, 2005). As poucas exceções compreendem espécies que habitam águas muito frias, como aquelas encontradas em regiões polares ou mar profundo, espécies que adquirem tamanhos corporais muito grandes, tais como as lulas gigantes do gênero Architeuthis, que levam cerca de três a quatro anos para atingirem seu tamanho máximo (Hanlon \& Messenger, 1996; Nixon \& Young, 2003; Boyle \& Rodhouse, 2005; Jereb \& Roper, 2010), e as espécies do gênero Nautilus, as quais podem viver mais de 20 anos (Saunders, 1984).

As inferências a respeito do tempo de vida dos cefalópodes - principalmente em lulas e sépias - são obtidas através de técnicas de estimativa de idade baseadas no uso de estatólitos (Boyle \& Rodhouse, 2005; Arkhipkin, 2005). Os estatólitos são estruturas calcárias pares presentes nos estatocistos, os quais são compostos por um par de cavidades preenchidas por líquido e localizados no interior da cartilagem cefálica (Boyle \& Rodhouse, 2005). O complexo formado pelo estatocisto e estruturas associadas compõe o sistema sensorial dos cefalópodes e auxilia na detecção de gravidade e movimento, de forma similar ao sistema de canais semicirculares dos vertebrados (Young, 1960; Rodhouse \& Hatfield, 1990; Arkhipkin \& Bizikov, 2000; Nixon \& Young, 2003; Boyle \& Rodhouse, 2005). As estimativas de idade a partir dos estatólitos são baseadas na presença de anéis concêntricos nessa estrutura, os quais foram descritos pela primeira vez por Clarke (1966). A proposição de que esses incrementos concêntricos são depositados de forma diária foi elaborada inicialmente por Lipinski et al. (1998) e já foi validada para diversas espécies de lula (e.g., Sepioteuthis lessionana, Jackson, 1989a; Todarodes pacificus, Nakamura \& Sakurai, 1991; Loligo vulgaris, Bettencourt et al., 1996; Loligo vulgaris reynaudii, Lipinski et al., 1998, Durholtz et al., 2002), inclusive para a espécie-modelo deste trabalho, Doryteuthis plei (Jackson \& Forsythe, 2002; Perez et al., 2006; Aguiar et al., 2012). Com a validação da periodicidade diária de deposição dos incrementos concêntricos, os estatólitos têm sido amplamente utilizados como uma ferramenta precisa e confiável para estudos de idade e crescimento em cefalópodes (e.g., Spratt, 1978; Kristensen, 1980; Natsukari et al., 1988; Jackson, 1989a, 1989b; Rodhouse \& Hatfield, 1990; Bettencourt et al., 1996; Arkhipkin, 1997, 2005; Jackson et al., 1997; Jackson \& Moltschaniwskyj, 1999; Rocha \& Guerra, 1999; Hoving \& Lipinski, 2015).

\subsection{Biologia reprodutiva}


Todos os cefalópodes são dioicos e realizam transferência indireta de espermatozoides por meio de espermatóforos (Marian, 2015). De forma geral, os machos da maioria das espécies apresentam maturação sexual rápida, com cerca de três a seis meses de vida, e são capazes de realizar cópulas e transferir espermatóforos por aproximadamente dois terços de sua vida. Já as fêmeas apresentam maturação sexual mais tardia em relação aos machos, com cerca de quatro a oito meses de vida (Hanlon \& Messenger, 1996). No entanto, para algumas espécies, já foi constatado que os machos podem copular com fêmeas ainda sexualmente imaturas (Nesis, 1995), e seus espermatozoides podem permanecer viáveis por longos períodos de tempo, sendo armazenados por metade ou até dois terços da vida da fêmea (Hanlon \& Messenger, 1996). Porém, em outras espécies, sabe-se que os machos copulam apenas com fêmeas maduras e a desova em geral é seguida brevemente pela morte da fêmea (Nixon \& Young, 2003).

De forma geral, os cefalópodes são classificados como semélparos, isto é, apresentam apenas um ciclo reprodutivo ao longo da vida. Devido ao tempo de vida curto da maioria das espécies, estimado entre alguns meses a cerca de dois anos, a iteroparidade parece inviável para a maior parte dos representantes da subclasse Coleoidea (Moltschaniwskyj, 1995), de forma que a semelparidade e apenas um evento de desova terminal em massa, seguido pela morte da fêmea, prevaleceu por muito tempo como regra geral para o grupo (Boyle \& Boletzky, 1996; Rodhouse, 1998). No entanto, essa visão clássica foi questionada após o surgimento de evidências crescentes de espécies capazes de produzir múltiplas desovas ao longo da vida (e.g., Harman et al., 1989; Nesis, 1995; Rocha \& Guerra, 1996; Maxwell et al., 1998; Maxwell \& Hanlon, 2000). Com o intuito de esclarecer as controvérsias a respeito das estratégias reprodutivas dos cefalópodes, Rocha et al. (2001) propuseram uma nova classificação, a qual inclui a existência de iteroparidade e diferentes níveis possíveis de semelparidade. O único grupo que englobaria espécies verdadeiramente iteróparas, isto é, aquelas que apresentam vários ciclos reprodutivos ao longo da vida e regeneração dos ovários entre os ciclos, seria o gênero Nautilus, para o qual há evidências de tempo de vida longo e ciclos reprodutivos anuais. Além disso, já foi verificado que as fêmeas de Nautilus sobrevivem após o evento de desova anual e apresentam crescimento somático e regeneração gonadal entre os ciclos consecutivos. As demais espécies de cefalópodes permanecem classificadas como semélparas, isto é, com apenas um ciclo reprodutivo ao longo da vida e sem regeneração dos ovários. No entanto, há uma variação de estratégias possíveis, sendo elas: $(i)$ desovas terminais, as quais podem se apresentar como uma única ou várias desovas 
intermitentes, ambas seguidas brevemente pela morte da fêmea; (ii) desovas múltiplas ao longo da mesma estação reprodutiva e (iii) desovas contínuas por um longo período da vida da fêmea, podendo se estender por até metade do seu ciclo de vida. As duas últimas estratégias descritas diferem das desovas terminais pois a fêmea pode, nesses casos, apresentar crescimento somático entre as desovas.

Entre os cefalópodes, o dimorfismo sexual é aparente em muitas espécies e está principalmente relacionado a diferenças de tamanho, forma do corpo, formato e coloração da gônada e até mesmo ao arranjo dos fotóforos (Hanlon \& Messenger, 1996; Nixon \& Young, 2003). Em Octopodiformes pelágicos, como os do gênero Argonauta, os machos são muito pequenos e apresentam um hectocótilo muito maior do que o corpo (Nesis, 1995; Marian, 2015). Em Nautilus e lulas da família Loliginidae, os machos são geralmente maiores; na espécie Doryteuthis plei, por exemplo, eles podem apresentar o dobro do tamanho das fêmeas (Hanlon \& Messenger, 1996). Além disso, muitas lulas da família Loliginidae são translúcidas, de forma que o testículo mostra-se como uma estrutura esbranquiçada e conspícua em machos, assim como as glândulas nidimentares acessórias, de coloração alaranjada ou avermelhada, são em geral visíveis em fêmeas (Arnold, 1962; Hanlon \& Messenger, 1996). Adicionalmente, a maioria dos machos possui um ou dois braços modificados, denominado hectocótilo, que auxilia no transporte do espermatóforo para o corpo da fêmea (Nesis, 1995). A estrutura e posição do hectocótilo são específicos para cada espécie e constituem um caráter taxonômico relevante (Hanlon \& Messenger, 1996).

\subsection{Anatomia do sistema reprodutor}

A anatomia do sistema reprodutor de machos e fêmeas varia entre os diferentes táxons, mas diversos aspectos da morfologia básica são similares a todos os cefalópodes (Mann, 1984). O sistema reprodutor básico das fêmeas dos cefalópodes é constituído por (1) um ovário único e mediano, localizado na região posterior da cavidade do manto, (2) o oviduto, que pode estar presente como uma estrutura única (Decapodiformes, com exceção de Oegopsida) ou como um par (Octopodiformes e Oegopsida) e (3) glândula(s) oviducal(is), responsável(is) pela secreção do revestimento interno da cápsula dos ovos (Decapodiformes) ou da substância cimentante utilizada para fixar os ovos no substrato (Octopodiformes). Os ovócitos são produzidos no ovário e, quando tornam-se totalmente maduros, destacam-se do 
epitélio germinativo, sendo acumulados temporariamente no celoma genital (e.g., sépias e polvos) ou no(s) oviduto(s) (e.g., lulas). Durante a desova, os ovócitos atravessam o canal do oviduto até atingirem a glândula oviducal. Nos Decapodiformes, as fêmeas apresentam também um par de glândulas nidimentares, localizadas na região mediana da cavidade do manto, as quais são responsáveis por secretar a substância gelatinosa externa que envolve a cápsula dos ovos (Boyle \& Rodhouse, 2005). Com exceção de Oegopsida, as glândulas nidimentares dos Decapodiformes apresentam também um par de glândulas acessórias na região anterodorsal. Essas glândulas acessórias são colonizadas por bactérias simbiontes, as quais são transmitidas às cápsulas dos ovos e, possivelmente, constituem mais uma forma de proteção aos embriões (e.g., Barbieri et al., 2001).

Em alguns Decapodiformes, como lulas e sépias, as fêmeas apresentam um receptáculo seminal na membrana peribucal, uma estrutura semelhante a uma bolsa de fundo cego, onde são armazenados espermatozoides viáveis. Nesses casos, durante a cópula, os machos transferem espermatóforos à membrana peribucal. Em lulas, os machos também podem transferir os espermatóforos diretamente para o interior da cavidade do manto, onde em geral são fixados nas membranas que delimitam a abertura do oviduto (Drew, 1911; Boyle \& Rodhouse, 2005). O local de deposição do espermatóforo em lulas depende da posição adotada durante a cópula (ver seção 2.4 - Comportamento Reprodutivo).

Em polvos, a fertilização é interna e ocorre na glândula oviducal - local onde os espermatozoides são armazenados temporariamente -, conforme os ovócitos são liberados do oviduto (Nesis, 1995). Em sépias e lulas, a fertilização dos ovócitos é classificada como externa ou "externa confinada" (Naud \& Havenhand, 2006). Em sépias, ela ocorre na membrana peribucal, onde os espermatozoides são liberados do receptáculo seminal. Em lulas, a fertilização dos ovócitos pode ocorrer tanto no interior da cavidade do manto como na membrana peribucal, local onde espermatozoides armazenados no receptáculo seminal podem ser liberados pela fêmea (Drew, 1911; Hanlon \& Messenger, 1996; Iwata et al., 2005, 2011; Buresch et al., 2009).

O sistema reprodutor masculino dos cefalópodes é basicamente constituído por (1) testículo único e mediano, localizado na região posterior da cavidade do manto, (2) vaso deferente, (3) órgão espermatofórico e (4) saco espermatofórico. Os espermatozoides são produzidos no testículo e, quando tornam-se maduros, são transportados até o órgão espermatofórico via vaso deferente. O órgão espermatofórico consiste em um complexo 
sistema de tubos convolutos e glandulares; nesse órgão os espermatozoides são empacotados, por meio de secreções, em espermatóforos, os quais são posteriormente armazenados no saco espermatofórico (ou saco de Needham) (Austin et al., 1964; Mann, 1984). Durante a cópula, os espermatóforos são transportados para a região terminal do saco espermatofórico (comumente denominada 'pênis' ou órgão terminal), localizada próximo à abertura do manto. Em muitas espécies, a transferência dos espermatóforos para o corpo da fêmea é realizada com auxílio do hectocótilo; no entanto, espécies que não possuem braços modificados transferem espermatóforos diretamente pelo 'pênis' (Hoving et al., 2014).

Os espermatóforos são estruturas tubulares, que apresentam um complexo sistema de membranas e túnicas envolvendo seus componentes (Marian \& Domaneschi, 2012). De forma geral, os espermatóforos são formados por três regiões distintas: (1) a massa espermática, a qual contém os espermatozoides e está localizada na região aboral (podendo ocupar metade a dois terços do comprimento total do espermatóforo); (2) o corpo cimentante, componente responsável pela fixação do espermatóforo na fêmea e (3) o aparato ejaculatório, constituído por complexas membranas e pelo filamento espiral (Drew, 1919; Austin et al., 1964; Marian \& Domaneschi, 2012). O aparato ejaculatório situa-se na região oral do espermatóforo e é envolto pelo capuz, o qual porta um longo filamento do capuz. Esses filamentos são responsáveis por engatilhar a "reação espermatofórica" (Marian, 2012a, 2012b, 2015).

Durante a cópula, a remoção do espermatóforo do interior do corpo do macho promove o início da reação espermatofórica, um processo complexo de evaginação das membranas e túnicas do espermatóforo e crucial para a extrusão da massa espermática e seu implante no interior do corpo da fêmea (Marian, 2012a, 2012b). Para alguns autores, apenas o contato do espermatóforo com a água do mar seria suficiente para estimular o início da reação; as diferenças osmóticas seriam responsáveis pela entrada de água na estrutura, o que resultaria no aumento da pressão hidrostática no interior de sua porção oral, desencadeando assim a reação (Drew, 1919; Takahama et al., 1991). Outros autores, no entanto, salientam que a tração do filamento do capuz, associada à rápida remoção dos espermatóforos do interior do corpo do macho por meio do hectocótilo, seria necessária para estimular a reação no exato momento da cópula (Marian, 2012a, 2012b). A tração do filamento seria transmitida para a região do capuz, causando sua ruptura e desencadeando de forma instantânea os processos seguintes, a pressão hidrostática sendo igualmente necessária para a conclusão da reação (Drew, 1911, 1919; Austin et al., 1964; Hoving et al., 2009; Marian, 2012a, 2012b). 
O tempo de duração da reação espermatofórica é variável. Em espécies de Decapodiformes, ela pode ocorrer em poucos segundos, enquanto que no polvo gigante do Pacífico, o processo todo pode se prolongar por uma a duas horas (Drew, 1919; Austin et al., 1964; Mann et al., 1970; Takahama et al.,1991; Marian, 2012a). Ao final da reação, o espermatóforo origina dois componentes distintos: (1) a cápsula vazia, estrutura composta pelas túnicas externa e mediana e por parte do aparato ejaculatório evertido e (2) o espermatângio, o qual contém o reservatório de espermatozoides (i.e., a massa espermática envolvida pela túnica interna evertida) e o corpo cimentante (Drew, 1919; Marian, 2012a). Em lulas Loliginidae, o implante efetivo do espermatângio no tecido interno da fêmea é proporcionado por substâncias adesivas produzidas pelo corpo cimentante (Drew, 1919; Austin et al., 1964; Marian, 2012a) e por mecanismos de ancoragem provenientes do aparato ejaculatório (Marian, 2012a). Ao término da reação espermatofórica, a liberação dos espermatozoides é iniciada a partir de uma abertura localizada na extremidade oposta ao corpo cimentante (i.e., oposta àquela implantada na fêmea) (Marian, 2012a).

\subsection{Comportamento reprodutivo}

Nos moluscos da classe Cephalopoda, a poligamia é a regra geral, com fêmeas e machos apresentando múltiplas cópulas com mais de um parceiro ao longo do período reprodutivo (Drew, 1911; Hanlon, 1998, Iwata et al., 2005). Portanto, a paternidade múltipla e a competição espermática parecem ser processos comuns nas espécies do grupo (Hanlon et al., 1997, 1999, 2002; Hall \& Hanlon, 2002; Naud et al., 2004; Buresch et al., 2001, 2009; Shashar \& Hanlon, 2013).

Entre os membros de Coleoidea, o comportamento reprodutivo de Octopodiformes é tipicamente distinto do observado em Decapodiformes. Polvos são animais solitários e há pouca interação entre indivíduos da mesma espécie. Há competição pelo acesso à fêmea, mas comportamentos agonísticos entre machos ou de cortejo são aparentemente limitados. Quando comparada a lulas e sépias, a cópula em polvos apresenta duração prolongada; além disso, as fêmeas investem muita energia e tempo no cuidado com os ovos (Hanlon \& Messenger, 1996). Dentre os Decapodiformes, as lulas caracterizam-se pela exibição de diversas formas de interações sociais com coespecíficos e comportamentos gregários, enquanto as sépias são essencialmente solitárias ao longo da maior parte do ciclo de vida (Hanlon \& Messenger, 
1996). Apesar das diferenças, ambas formam agregados em áreas comuns de desova durante a estação reprodutiva, nos quais um grande número de indivíduos sexualmente ativos envolvese em comportamentos sexuais complexos, cópulas múltiplas e interações agonísticas entre machos (Hanlon, 1996, 1998; Hanlon et al., 1999, 2002, 2005; Naud et al., 2004; Shaw \& Sauer, 2004; Shashar \& Hanlon, 2013).

Em sépias, a cópula ocorre sempre na posição frontal (head-to-head; Hanlon et al., 1999; Hall \& Hanlon, 2002; Naud et al., 2004, 2005). Já em lulas da família Loliginidae, além da cópula na posição frontal, machos podem executar cópulas paralelas (male-parallel), nas quais eles posicionam-se sob o corpo da fêmea. De forma geral, machos de tamanhos grandes - isto é, maiores do que as fêmeas - pareiam-se temporariamente com as parceiras e realizam cópulas na posição paralela, depositando os espermatóforos na cavidade do manto da fêmea, próximo à abertura do oviduto (Arnold, 1962; Hanlon, 1996, 1998; Hanlon et al., 1997, 2002; Shaw \& Sauer, 2004; Iwata et al., 2005; Buresch et al., 2009; Zeidberg, 2009; Shashar \& Hanlon, 2013). Eles tendem a permanecer próximos às suas parceiras antes e depois do acasalamento - às vezes até o momento da postura de ovos, defendendo-as do assédio de outros machos grandes. Machos menores - em geral de tamanho similar ou menores que as fêmeas -, por sua vez, não se engajam em combates físicos com outros machos, mas tentam copular furtivamente com as fêmeas na posição frontal, em geral sem resistência do macho dominante. Nesse caso, os espermatóforos são posicionados próximos ao receptáculo seminal, na membrana peribucal (Arnold, 1962; Hanlon, 1996, 1998; Hanlon et al., 1997, 2002; Shaw \& Sauer, 2004; Iwata et al., 2005, 2011; Buresch et al., 2009; Zeidberg, 2009; Shashar \& Hanlon, 2013).

Tanto observações em ambiente natural quanto as obtidas em laboratório indicam que fêmeas, mesmo imaturas ou de pequeno tamanho, podem ser encontradas com espermatozoides armazenados no receptáculo seminal, o que sugere que cópulas na posição frontal são frequentes e podem ocorrer ao longo de um período considerável da vida das fêmeas, mesmo antes dessas chegarem às áreas comuns de desova (Drew, 1911; Hanlon, 1996, 1998; Hanlon et al., 1999, 2002; Shaw \& Sauer, 2004; Iwata et al., 2005; Shashar \& Hanlon, 2013). Já as cópulas na posição paralela são, em geral, seguidas quase imediatamente pela postura de ovos (Drew, 1911; Arnold, 1962). 


\subsection{Seleção sexual em cefalópodes}

Em cefalópodes, especialmente em lulas e sépias, os mecanismos clássicos de seleção sexual por meio da competição intrassexual entre machos são bastante evidentes. Como já descrito na seção anterior, em diversas espécies os machos apresentam interações agonísticas entre coespecíficos em tentativas de monopolizar o acesso às fêmeas. De forma geral, os comportamentos podem ser por meio de sinalizações visuais - e.g., pela exibição de diferentes padrões de coloração por meio da ação dos cromatóforos - ou combates físicos, os quais podem envolver perseguições e fuga e até mesmo lutas empregando a região posterior do corpo (Hanlon \& Messenger, 1996; DiMarco \& Hanlon, 1997). Os mecanismos de escolha direta da fêmea, no entanto, são menos elucidados. Há relatos de rejeições à cópula exercidas pela fêmea (Hanlon, 1998; Hall \& Hanlon, 2002; Hanlon et al., 2002, 2005; Naud et al., 2004; Buresch et al., 2009; Shashar \& Hanlon, 2013), mas não há evidências robustas a respeito de preferência de parceiros ou seleção de caracteres morfológicos atrativos às fêmeas. Para Hanlon \& Messenger (1996), é possível que os padrões de coloração exibidos pelos machos possam sinalizar boas condições físicas e vigor às fêmeas.

Diversos aspectos da biologia reprodutiva dos cefalópodes têm evidenciado de forma substancial a existência de competição espermática e a possibilidade de seleção críptica da fêmea no grupo. Dentre eles, destacam-se: a poligamia; a guarda da fêmea antes e depois da cópula; longos intervalos entre as inseminações e a postura de ovos; e a adoção de diferentes posições de cópula, associadas a aspectos anatômicos da fêmea, como a possibilidade de armazenamento de espermatozoides por longos períodos e em sítios especializados (e.g., no receptáculo seminal) (Cigliano, 1995; Hanlon \& Messenger, 1996; Baur, 1998; Hanlon, 1998; Hanlon et al., 1999; Hall \& Hanlon, 2002; Naud et al., 2004, 2005, 2016; Iwata et al., 2005; Buresch et al., 2009; Sato et al., 2013).

Como descrito anteriormente neste capítulo, uma das principais consequências da competição espermática está relacionada à evolução de comportamentos adaptativos apresentados pelos machos na tentativa de reduzir a disputa pela paternidade dos ovócitos e aumentar seu sucesso reprodutivo (Birkhead \& Møller, 1998). Em sépias, por exemplo, um mecanismo possível para reduzir a competição espermática pode estar relacionado ao comportamento dos machos de lançar jatos de água na região bucal da fêmea, ação que pode durar mais da metade do tempo total de cópula. Essa atividade pode permitir a remoção de espermatângios implantados ou de espermatozoides armazenados no receptáculo seminal 
provenientes de cópulas prévias (Hanlon et al., 1999; Hall \& Hanlon, 2002; Naud et al., 2004, 2005). Em polvos, os machos são capazes de acessar o histórico recente de cópulas de determinada fêmea pela presença de espermatozoides no interior do canal do oviduto. Como consequência, esses indivíduos podem intensificar a duração da cópula, possivelmente para remover espermatozoides de cópulas anteriores com auxílio do hectocótilo (Cigliano, 1995).

Em lulas da família Loliginidae, as quais apresentam dois sítios para deposição de espermatóforos (i.e., na membrana peribucal, próximo ao receptáculo seminal, e no interior da cavidade do manto, próximo à saída do oviduto), o sucesso de fertilização dos espermatozoides localizados em diferentes porções do corpo da fêmea deve ser desigual (e.g., Iwata et al., 2005; Naud et al., 2016). Além disso, com a existência desses dois sítios, há possibilidade de seleção críptica da fêmea. Nessas espécies, é possível que a fêmea exerça algum controle ou poder de decisão sobre a utilização dos espermatozoides armazenados no interior do receptáculo seminal (Hanlon et al., 1997; Hanlon, 1998; Shaw \& Sauer, 2004; Naud et al., 2016) e, consequentemente, sobre o sucesso de machos que executam cópulas na posição frontal (Shashar \& Hanlon, 2013; Naud et al., 2016). Além disso, há possibilidade das fêmeas serem capazes de manipulação ou até mesmo ejeção de espermatângios implantados no interior da cavidade do manto (i.e., oriundos de machos que executam cópulas paralelas), por meio do controle da intensidade ou frequência das contrações do manto durante a expulsão de água (Buresch et al., 2009).

Estudos empregando manipulações experimentais e análises de paternidade com a espécie Loligo pealeii (família Loliginidae) permitiram integrações importantes entre competição espermática e os interesses da fêmea. Buresch et al. (2009) verificaram a importância do intervalo entre cópula e postura dos ovos na determinação do sucesso reprodutivo dos machos. Assim como relatado para outros táxons animais, se o intervalo entre os eventos for curto, o primeiro macho a copular apresenta maior sucesso na paternidade da progênie; no entanto, se o intervalo for extenso, o último macho a copular apresenta maior sucesso (Birkhead \& Møller, 1998). Portanto, caso as fêmeas de cefalópodes sejam capazes de exercer alguma forma de controle sobre a postura dos ovos, é possível que haja escolha indireta sobre qual macho terá maior paternidade de sua progênie (Buresch et al., 2009).

Além da família Loliginidae, evidências de seleção críptica da fêmea foram descritas para a espécie Idiosepius paradoxus (família Idiosepiidae). Nessa espécie, os machos 
depositam espermatóforos na região dos braços das fêmeas, as quais são capazes de remover e até mesmo ingerir os espermatângios implantados (Sato et al., 2013).

\subsection{Táticas Alternativas de Reprodução e Dimorfismo intrassexual}

A forte competição entre machos pode resultar na evolução de táticas alternativas de reprodução. Indivíduos que apresentam menor sucesso que seus oponentes podem optar pela adoção de estratégias divergentes para aumentar sua aptidão reprodutiva (e.g., Gross, 1996; Taborsky et al., 2008). Em cefalópodes, a exibição de táticas alternativas já foi registrada para espécies de lulas e sépias e está associada a diferenças fenotípicas nos machos (i.e., dimorfismo intrassexual), principalmente relacionadas ao tamanho corporal dos indivíduos (Hanlon \& Messenger, 1996; Iwata \& Sakurai, 2007). Nesses dois grupos de cefalópodes, são encontradas duas estratégias básicas de reprodução: (i) táticas dominantes, com guarda da fêmea e combate entre machos, executadas por machos maiores (chamados de consorts) e (ii) táticas furtivas, desempenhadas por machos menores (chamados de sneakers), que apresentam tamanhos similares ou até menores que as fêmeas (e.g., Hanlon, 1996, 1998; Hanlon et al., 1997, 2002; Hall \& Hanlon, 2002; Naud et al., 2004; Iwata et al., 2005; Shashar \& Hanlon, 2013).

Em sépias, machos sneaker podem exibir táticas diversas para obter sucesso reprodutivo. Esses indivíduos podem tentar executar cópulas furtivas com as fêmeas enquanto os machos consort estão envolvidos em disputas físicas, durante o momento da desova ou até mesmo mimetizando o comportamento e aparência das fêmeas (Hall \& Hanlon, 2002; Naud et al., 2004, 2005; Hanlon et al., 2005). Em lulas, machos consort executam cópulas tipicamente na posição paralela, depositando espermatóforos próximos ao oviduto, enquanto machos sneaker executam cópulas na posição frontal e depositam espermatóforos próximos ao receptáculo seminal (e.g., Hanlon, 1996, 1998; Hanlon et al., 1997, 2002; Buresch et al., 2001, 2009; Iwata et al., 2005; Shashar \& Hanlon, 2013).

Em lulas da família Loliginidae, o dimorfismo intrassexual tem sido investigado extensivamente na espécie Heterololigo bleekeri. Além de diferenças na morfologia dos espermatângios (Iwata et al., 2014), estudos com essa espécie evidenciaram que machos consort produzem espermatóforos significativamente maiores e uma quantidade de espermatozoides maior do que os sneakers (Iwata \& Sakurai, 2007; Iwata et al., 2011). 
Machos sneaker, por outro lado, produzem espermatozoides relativamente maiores, os quais tendem a se agregar por quimioatração quando liberados, provavelmente movendo-se como uma massa única em direção ao receptáculo seminal feminino (Hirohashi \& Iwata, 2013; Hirohashi et al., 2013).

Essas observações em Heterololigo bleekeri não se enquadram na teoria clássica de competição espermática, a qual prediz que machos menores devem apresentar um maior investimento espermático quando comparados aos machos maiores, uma vez que sofrem maior risco de competição espermática (Parker, 1990b; Iwata \& Sakurai, 2007; Iwata et al., 2011; Hirohashi \& Iwata, 2013). Iwata et al. (2011) sugeriram que as diferenças entre espermatozoides de consorts e sneakers de H. bleekeri poderiam estar relacionadas a pressões seletivas divergentes associadas aos respectivos locais de deposição de espermatóforos no corpo das fêmeas (e.g., diferenças de salinidade, pH, concentração de gases ou nutrientes, risco de diluição).

\section{Justificativa}

Em lulas, há evidências - tanto de observações em campo quanto em laboratório - da adoção de táticas alternativas de reprodução em machos (e.g., Hanlon \& Messenger, 1996; Hanlon, 1996, 1998; Hanlon et al., 1997, 2002; Iwata et al., 2005). Machos de maior tamanho (consorts) estão associados a comportamentos agressivos e cópulas paralelas, enquanto machos de menor tamanho (sneakers) apresentam estratégias furtivas e cópulas frontais. No entanto, a maioria dos estudos limita-se à relação entre adoção de determinada tática ao tamanho do indivíduo; há poucos trabalhos que tenham investigado de forma mais extensa a presença de descontinuidades morfológicas e a existência de dimorfismo intrassexual masculino considerando caracteres externos e internos.

Os trabalhos relacionados à presença de dimorfismo intrassexual em machos, associado às táticas alternativas de reprodução, são restritos a somente uma espécie até o momento (H. bleekeri; Iwata \& Sakurai, 2007; Iwata et al., 2011, 2014). Especificamente sobre a descontinuidade de caracteres internos, os estudos existentes limitam-se a diferenças morfológicas quanto ao aspecto geral (e.g., tamanho e formato) de espermatóforos e espermatângios em machos de diferentes tamanhos; não há estudos que tenham comparado a morfologia detalhada dessas estruturas ou o funcionamento dos espermatóforos. 
O depósito de espermatóforos em diferentes sítios no interior do corpo da fêmea (i.e., próximo à membrana peribucal ou nas membranas próximas à abertura do oviduto), associado ao intervalo entre cópulas e desova e ao local de fertilização dos ovócitos, pode resultar em sucesso desigual entre machos que executam diferentes táticas. Além disso, observações em ambiente natural mostram que fêmeas podem participar de diversas cópulas frontais, antes mesmo de chegarem ao local de desova. Esse acúmulo de informações gera questionamentos a respeito de possíveis mecanismos que permitem aos espermatozoides de machos sneaker resistirem por longos períodos de tempo até o momento da deposição dos ovos pela fêmea. Em H. bleekeri, foram investigadas somente as diferenças de tamanho entre espermatozoides de machos consort e sneaker, as quais foram associadas aos diferentes sítios de implante na fêmea. No entanto, nunca foram investigadas possíveis diferenças entre o mecanismo e o tempo de liberação de espermatozoides a partir de espermatângios de machos de maior ou menor tamanho.

Além da existência de poucos trabalhos relacionados a diferenças morfológicas, investigações a respeito do investimento em produtos ejaculatórios entre indivíduos que adotam diferentes tipos de cópula em $H$. bleekeri revelaram que machos sneakers apresentam investimento menor do que os machos consorts (i.e., machos sneakers produzem espermatóforos menores, espermatozoides maiores e menor quantidade de espermatozoides por espermatóforo que machos consorts), resultados que contradizem os modelos teóricos de competição espermática (Iwata \& Sakurai, 2007; Iwata et al., 2011). No entanto, esses estudos limitaram-se à utilização de dados morfométricos de espermatozoides e espermatóforos. Abordagens relacionadas ao tamanho relativo do testículo - hoje considerado um excelente índice para mensurar o nível de competição espermática enfrentada por determinada espécie ou população (e.g., Gage \& Freckleton, 2003) - ainda são inexistentes para lulas.

À época da redação do projeto de pesquisa que resultou na presente dissertação, algumas evidências já sugeriam que o dimorfismo intrassexual masculino estivesse presente em Doryteuthis plei, alvo deste estudo. Primeiramente, machos dessa espécie apresentam uma distribuição polimodal de tamanho (Perez et al., 2002). Além disso, algumas características comportamentais e morfológicas associadas ao dimorfismo intrassexual de H. bleekeri (e.g., Iwata \& Sakurai, 2007) foram observadas em D. plei. Machos dessa espécie podem efetuar tanto cópulas frontais quanto paralelas (Hanlon \& Messenger, 1996; Marian, 2012a) e foram observadas diferenças morfológicas quanto ao aspecto geral de espermatângios depositados 
na membrana peribucal e aqueles encontrados próximos à abertura do oviduto (Marian, 2012a).

Apesar do grande número de estudos relacionados ao dimorfismo masculino em diversas espécies de animais, há pouca documentação sobre os possíveis mecanismos responsáveis pela expressão de fenótipos alternativos (e.g., Shuster \& Wade, 1991; Radwan, 1995; Alonzo et al., 2000; Smallegange, 2011), sendo que as táticas podem ser fixas ou flexíveis ao longo da vida do indivíduo (ver item 1.2; Gross, 1996). Estudos relacionados à adoção de táticas alternativas em peixes e estimativas de idade de machos dimórficos mostraram resultados promissores para a compreensão dos mecanismos relacionados à determinação do dimorfismo intrassexual masculino no grupo (e.g., Dominey, 1980; Alonzo et al., 2000; Mazzoldi et al., 2000). A partir do uso de incrementos diários depositados em otólitos, observou-se que, em algumas espécies, a adoção da tática é fixa ao longo da vida e machos que adotam estratégias divergentes apresentam tamanhos diferentes, mas não expressam diferença de idade (Dominey, 1980). Por outro lado, em outras espécies, os machos podem apresentar uma combinação entre táticas flexíveis e fixas: machos de tamanho pequeno podem adotar táticas furtivas na primeira estação reprodutiva (i.e., com um ano de idade) e alternar para a tática dominante na estação seguinte (i.e., com dois anos de idade), enquanto outros machos investem apenas em crescimento durante o primeiro ano de vida e atrasam a maturação reprodutiva, assumindo somente a tática dominante com dois anos de idade (Alonzo et al., 2000).

Em lulas, até o momento não há estudos que relatem mudanças de comportamento ao longo de seus ciclos de vida ou que tenham investigado a idade média de cada classe de machos. Nesses animais, já foi verificada a ocorrência de deposição diária de incrementos concêntricos nos estatólitos - inclusive para Doryteuthis plei -, de forma similar ao que acontece em otólitos de peixes. Dessa forma, é possível utilizar essas estruturas para obtenção de estimativas da idade dos indivíduos. Diferenças de idade entre os machos podem refletir a adoção de táticas flexíveis ou táticas fixas - ou a combinação de ambas (e.g., Alonzo et al., 2000). As táticas fixas podem emergir, por exemplo, como resultado de diferentes taxas de maturação; machos sneaker podem atingir a maturidade mais cedo que consorts, os quais, com taxas mais lentas, atingem tamanhos corporais maiores mais tardiamente (e.g., Gross, 1991; Alonzo et al., 2000; Smallegange \& Johansson, 2014). De forma alternativa, é possível também que os indivíduos adotem estratégias flexíveis, condicionais a seu tamanho corporal. Como cefalópodes apresentam crescimento contínuo ao longo da vida, é possível que alguns 
indivíduos expressem táticas furtivas enquanto apresentam tamanhos pequenos, mas alternem para táticas dominantes ao ultrapassarem determinado limiar de tamanho. Este trabalho, portanto, poderá contribuir para o início da compreensão dos mecanismos relacionados à determinação do dimorfismo intrassexual masculino no grupo.

\section{Objetivos}

O objetivo geral deste trabalho foi investigar de forma detalhada a existência de dimorfismo intrassexual masculino na espécie Doryteuthis plei e os possíveis mecanismos envolvidos na determinação deste dimorfismo. Mais especificamente, foram respondidas as seguintes perguntas:

(1) Machos de diferentes tamanhos (consorts vs. sneakers) diferem em relação ao investimento gonadal (peso do sistema reprodutor, comprimento relativo da massa espermática contida no espermatóforo)?

(2) Machos de diferentes tamanhos (consorts vs. sneakers) diferem em relação à morfologia e morfometria de espermatóforos intactos e evertidos e espermatozoides e quanto ao tempo de liberação de espermatozoides a partir de espermatângios?

(3) As diferenças morfológicas entre machos de diferentes tamanhos (consorts vs. sneakers) são determinadas pela idade dos indivíduos?

\section{Metodologia básica}

\subsection{Coleta dos exemplares}

As coletas foram realizadas ao longo dos meses de verão (dezembro a fevereiro) entre os anos de 2014 e 2016 ao largo do litoral norte da Ilha de São Sebastião (2344’00" S e $45^{\circ} 17^{\prime} 50^{\prime}$ W), município de Ilhabela, São Paulo. Ao todo, foram coletados 287 machos sexualmente maduros, entre 88 e $327 \mathrm{~mm}$ de comprimento do manto. Os espécimes de Doryteuthis plei foram capturados com técnicas de pesca artesanal de lulas utilizando “zangarelhos”, instrumentos compostos por anzóis chumbados. Após a captura, os espécimes foram acondicionados na embarcação em porões contendo água do mar, até serem 
encaminhados aos laboratórios do Centro de Biologia Marinha da USP (CEBIMar - USP). Os indivíduos que não sobreviveram ao período de coleta foram removidos dos porões e armazenados em caixas térmicas com gelo até o retorno ao CEBIMar.

Nos laboratórios do CEBIMar, o qual dispõe de um sistema de captação e distribuição de água do mar, as lulas foram alojadas em tanques com água do mar circulante e capacidade de 500-1000 L. Os espécimes foram mantidos nos tanques e alimentados com camarões frescos até o momento de processamento de cada indivíduo. Para anestesia, cada espécime foi retirado do tanque com auxílio de um puçá e transferido para uma cuba de plástico contendo duas partes de água do mar e uma parte de solução de cloreto de magnésio a 7.5\% (preparado em água destilada). Após constatação de total ausência de movimentos e reações ao toque (aproximadamente 10 minutos), os indivíduos foram retirados da solução anestésica e processados.

Para este estudo, foram selecionados apenas indivíduos do sexo masculino classificados como sexualmente maduros; a determinação do estágio de maturidade foi baseada na escala de maturidade descrita em Perez et al. (2002). Além disso, é necessário ressaltar que todos os métodos de coleta, manutenção e anestesia dos espécimes seguiram as orientações de literatura especializada (Moltschaniwskyj et al., 2007).

Por se tratar de um estudo com o objetivo de investigar diferenças morfológicas e morfométricas entre machos sexualmente maduros de diferentes tamanhos, mostrou-se necessária a complementação da amostragem com a compra de exemplares frescos de pequeno tamanho, uma vez que estes mostraram-se mais raros em nossas coletas. Os exemplares foram comprados de pescadores locais que se encontravam na área de coleta e foram selecionados, dentre os indivíduos de pequeno tamanho, apenas aqueles que tivessem sido capturados ao longo do mesmo dia. Em laboratório, os exemplares frescos mostraram-se bem preservados quanto aos órgãos internos e foram incluídos nas análises morfométricas descritas adiante. No entanto, estes indivíduos não foram utilizados para experimentos in vitro ou para análises histológicas. 


\subsection{Morfometria}

Para todos os indivíduos coletados foram efetuadas medidas de comprimento total do manto, comprimento do hectocótilo e peso úmido total. A obtenção de dados de comprimento e peso foram seguidas pela dissecção e extração do sistema reprodutor, para o qual foram realizadas medições do peso total (testículo + complexo espermatofórico + pênis) e do testículo separadamente. O complexo espermatofórico compreende duas estruturas distintas, o órgão espermatofórico e o saco espermatofórico (ou saco de Needham), responsáveis pela produção e armazenamento de espermatóforos, respectivamente. Em seguida, o saco espermatofórico foi dissecado para extração dos espermatóforos e obtenção de espermatângios, os quais foram fixados em fixador de Karnovsky (paraformaldeído a 2\% e glutaraldeído a 2.5\% em tampão cacodilato de sódio a $0.1 \mathrm{M}, \mathrm{pH} 7.4, \mathrm{CaCl}_{2} 2.5 \mathrm{mM}$, ajustado a 1000 mOsm com sacarose) para análises morfológicas e histológicas.

Para morfometria de espermatozoides, espermatóforos de machos vivos anestesiados foram engatilhados in vitro sob estereomicroscópio. Após ocorrência da reação espermatofórica, uma amostra dos espermatozoides liberados foi recolhida com pipeta e fixada em tubos de $1.5 \mathrm{ml}$ contendo paraformaldeído a 4\% (em tampão PBS a $0.1 \mathrm{M}, \mathrm{pH} 7.2$, $4^{\circ} \mathrm{C}$ ). Após a fixação, um volume de $60 \mu 1$ da suspensão de espermatozoides de cada indivíduo foi submetido a citocentrífuga $(10,000 \mathrm{rpm} ; 5$ minutos) para preparo de lâminas permanentes; esse procedimento permitiu a concentração de espermatozoides e sua adesão em lâminas de microscopia. Após esse procedimento, as lâminas foram coradas com Azul de Toluidina (3 minutos) para evidenciar de forma satisfatória o comprimento total dos flagelos, sendo finalmente montadas com meio de montagem e lamínula. Por fim, as medidas do comprimento da cabeça e do flagelo de espermatozoides foram obtidas com auxílio de microscópio óptico, sob aumento de 630×, acoplado a um sistema de captura de imagens. Ao todo, foram medidos 20 espermatozoides por indivíduo, de um total de 60 machos (consorts, $\mathrm{N}=30$; sneakers, $\mathrm{N}=30$ ).

\subsection{Morfologia e histologia}

Amostras de espermatóforos e espermatângios foram fixadas em solução de paraformaldeído a 4\% ou fixador de Karnovsky (ver acima) para análises morfológicas e histológicas. 
Após a fixação, foram selecionados cinco espermatóforos intactos de cada indivíduo para tomada de medidas precisas de cada região do espermatóforo. As medidas incluíram: comprimento total do espermatóforo $(\mathrm{SpL})$, comprimento do aparato ejaculatóro (EAL), comprimento do corpo cimentante (CBL), comprimento da massa espermática (SML), diâmetro do espermatóforo na região intermediária do corpo cimentante $(\mathrm{SpD})$, diâmetro da região intermediária do corpo cimentante (CBD) e diâmetro da massa espermática (SMD). Para cada indivíduo, foram calculados a média e o desvio padrão para cada medida. Por fim, esses dados foram utilizados para estimativa do volume da massa espermática e cálculo dos seguintes índices: $\mathrm{EALI}=(\mathrm{EAL} / \mathrm{SpL})(100) ; \mathrm{CBLI}=(\mathrm{CBL} / \mathrm{SpL})(100) ; \mathrm{SMLI}=$ $(\mathrm{SML} / \mathrm{SpL})(100) ; \mathrm{CBDI}=(\mathrm{CBD} / \mathrm{SpD})(100)$.

Para as análises histológicas, as amostras de espermatóforos e espermatângios foram posteriormente desidratadas e incluídas em resina à base de glicol metacrilato (historresina). Cortes sagitais e transversais de $3 \mu \mathrm{m}$ foram submetidos a diversos procedimentos de coloração (de acordo com Humanson, 1962; Bancroft \& Stevens, 1982; Pearse, 1985), tais como Hematoxilina de Mayer e Eosina aquosa (H\&E), Ácido Periódico e Reativo de Schiff (PAS), Azul de Alcian pH 2.5 e Azul de Bromofenol. Além disso, combinações entre as técnicas de coloração de H\&E e PAS também foram testadas para cortes de espermatângios.

\subsection{Experimentos in vitro}

Para os experimentos in vitro, espermatóforos frescos extraídos do saco espermatofórico de indivíduos vivos anestesiados foram transferidos para placas de Petri contendo água do mar filtrada e então engatilhados. O processo de reação espermatofórica foi cronometrado e registrado por meio de filmagens. Após o fim da reação espermatofórica, mensurou-se também o intervalo de tempo no qual ocorreu liberação de espermatozoides a partir do espermatângio. Ambos os experimentos foram realizados sob estereomicroscópio e registrados através do sistema de fotos e filmagem acoplado ao equipamento óptico.

\subsection{Estimativas de idade}

Para análises de estimativa de idade dos indivíduos coletados, o par de estatólitos de cada espécime foi dissecado a partir da região da cartilagem cefálica e armazenado em álcool 
a 70\%. Para visualização dos anéis de crescimento, um dos estatólitos de cada par foi preparado de acordo com a metodologia descrita em Perez et al. (2006) e Schwarz \& Perez (2010). O estatólito foi fixado a uma lâmina com esmalte incolor, mantendo a porção convexa exposta. Esta porção foi então polida com auxílio de lixas d'água P1200 (Norton), P1500 (Doble-A), P2000 (3M) e P3000 (3M), em ordem decrescente de abrasão, até que fosse possível visualizar as deposições concêntricas dos incrementos ao longo de toda a extensão do estatólito, desde o núcleo até a extremidades dos domos dorsal e lateral.

O estatólito foi analisado com auxílio de microscópio óptico acoplado a um sistema de captura de imagens. Imagens sucessivas da estrutura, realizadas sob aumento de $1000 \times$ e uso de óleo de imersão, foram utilizadas para as contagens. As estimativas de idade foram obtidas através de três contagens independentes dos incrementos diários para cada estatólito, feitas por um único leitor. A precisão das contagens foi verificada pela porcentagem média de erro (APE; Beamish \& Fournier, 1981), que expressa o desvio percentual de cada contagem da contagem média, e pelo coeficiente de variação (CV; Chang, 1982), que expressa o desvio padrão dividido pela média.

\section{Organização da dissertação}

A Dissertação está organizada em um total de cinco capítulos. O primeiro e último capítulos ("Introdução" e "Considerações Finais", respectivamente) estão redigidos em português, enquanto que os demais estão estruturados no formato de artigos científicos e na língua inglesa. Todas as tabelas e figuras pertinentes, assim como anexos e referências citadas, estão organizadas ao final de cada capítulo. Com exceção ao primeiro e último capítulo, as referências citadas em cada capítulo estão padronizadas de acordo com as normas requisitadas por cada periódico internacional para o qual cada manuscrito será (ou já foi) submetido. Além disso, ao início de cada capítulo, com exceção ao primeiro e último, consta um resumo expandido, em português, no qual estão sintetizados os principais objetivos, resultados e conclusões daquela seção da dissertação. Os vídeos suplementares citados ao longo do presente trabalho encontram-se em CD anexo à Dissertação. 
O capítulo "Dimorphic male squid show differential gonad and ejaculate expenditure" evidencia a existência de dimorfismo intrassexual em machos de Doryteuthis plei, revelando a presença de descontinuidades morfológicas quanto a aspectos morfológicos e morfométricos do espermatóforo intacto, espermatângio (i.e., espermatóforo evertido) e espermatozoide entre machos maduros de diferentes tamanhos. Além disso, esse capítulo investiga a existência de investimento gonadal diferencial entre machos dimórficos, associado a adoção de táticas alternativas de reprodução, e discute os resultados obtidos com base nas predições relacionadas aos modelos teóricos de competição espermática. Esse manuscrito foi submetido ao periódico internacional Hydrobiologia em setembro de 2016.

O capítulo subsequente, "Dimorphic squid ejaculates and sperm strategies associated with alternative mating behaviors", descreve as diferenças relacionadas aos produtos ejaculatórios entre machos dimórficos (sneaker e consort) na espécie. Esse capítulo abrange descrições morfológicas de espermatóforos intactos e evertidos, baseadas em técnicas de microscopia de luz e testes histoquímicos. Além disso, inclui os resultados obtidos por meio de experimentações in vitro a respeito do mecanismo e duração da reação espermatofórica e tempo de liberação de espermatozoides a partir de espermatângios. Esse manuscrito será submetido ao periódico internacional Journal of Morphology.

O capítulo "From sneaky to bully: evidence for ontogenetic tactics in dimorphic male squid" compreende uma extensão do capítulo anterior e relata a existência de machos raros obtidos durante as coletas e que apresentam, simultaneamente, espermatóforos com morfologia similar a de machos sneaker e machos consort, além de estruturas com morfologia intermediária entre ambos os morfotipos. Esse capítulo também abrange investigações a respeito da estimativa de idade de machos dimórficos na espécie, obtidas por meio da contagem de incrementos depositados de forma diária em estatólitos. Com base nos resultados apresentados nesse capítulo, propõe-se uma hipótese ontogenética para explicar a existência de fenótipos alternativos de reprodução na espécie (i.e., dimorfismo morfológico e comportamental), na qual machos de diferentes idades (e tamanhos) adotam diferentes táticas para assegurar sucesso reprodutivo. Esse manuscrito será submetido ao periódico internacional Proceedings of the Royal Society of London B: Biological Sciences. 


\section{Conclusões}

A presente Dissertação de Mestrado revelou a existência de dimorfismo intrassexual em machos da espécie Doryteuthis plei (Cephalopoda: Loliginidae), o qual foi caracterizado com base nas diferenças quanto a morfologia e funcionamento de estruturas reprodutivas entre machos dimórficos. Como descrito em detalhes a seguir, o presente trabalho traz importantes contribuições à compreensão da competição espermática em lulas, além de incluir aspectos iniciais sobre os possíveis mecanismos responsáveis pela determinação e expressão de fenótipos dimórficos no grupo, sendo ambos os assuntos pertencentes a um campo bastante desconhecido para cefalópodes de uma forma geral.

A existência de táticas alternativas de reprodução (consorts vs. sneakers), associada a diferenças comportamentais quanto ao tipo de cópula (paralela vs. frontal), deposição de espermatóforos (próximos ao oviduto $v s$. próximos ao receptáculo seminal) e estratégia reprodutiva (monopolização de fêmeas vs. táticas furtivas) já havia sido previamente descrita na literatura para a espécie de estudo (Hanlon \& Messenger, 1996), de forma similar a outras espécies da família Loliginidae (e.g., Hanlon et al., 1997, 2002; Iwata \& Sakurai, 2007), e reforçada por observações quanto à configuração distinta de espermatângios (i.e., espermatóforos evertidos) depositados em diferentes sítios da fêmea (Marian, 2012). Porém, nenhum trabalho prévio havia associado a existência de táticas alternativas de reprodução a machos dimórficos, i.e., a machos que apresentassem descontinuidades morfológicas e/ou fisiológicas associadas à exibição de comportamentos alternativos. Nesse contexto, o presente trabalho foi inédito ao identificar que morfologias descontínuas quanto à estrutura dos espermatóforos (i.e., a proporção de massa espermática contida em seu interior) e espermatângios (i.e., formato de anzol $v$ s. formato de clava) estavam relacionadas a machos de diferentes tamanhos e também à adoção de comportamentos alternativos de reprodução.

No presente trabalho, o estabelecimento de um switch point para tamanho corporal, associado às morfologias distintas do espermatóforo, permite que cada indivíduo amostrado da população seja facilmente classificado como sneaker ou consort, dentro de uma possível margem de erro, apenas com base no comprimento do manto. Essa informação permitirá um avanço na realização de estudos futuros que abordem aspectos comportamentais de machos sneakers e consorts em laboratório, uma vez que dispensam a necessidade de adoção de 
técnicas invasivas ou da morte do animal para dissecção de espermatóforos. No entanto, é necessário ressaltar que a extrapolação do switch point encontrado no presente trabalho para outras populações de D. plei existentes ao longo da costa Sul e Sudeste do Brasil deve ser realizada com cautela. Os fatores que influenciam a evolução e manutenção de switch points em determinada população compreendem um tema complexo e relativamente desconhecido (e.g., Tomkins \& Hazel, 2007), o qual diverge do escopo abordado neste trabalho. Porém, estudos prévios com outros táxons apontam que fatores ambientais e demográficos (i.e., densidade populacional), por exemplo, podem influenciar o sucesso reprodutivo de cada tática, e, consequentemente, modificar o switch point de determinada população ao longo do tempo e do espaço (Tomkins \& Brown, 2004).

A elaboração e corroboração das premissas teóricas dos modelos de competição espermática em espécies que apresentam táticas alternativas de reprodução (e.g., Parker, 1990) têm sido em sua maioria desenvolvidos a partir de estudos com um grupo restrito de táxons, limitando-se a espécies terrestres (como artrópodes e vertebrados; e.g., Simmons et al., 1999, 2007; Tomkins \& Simmons, 2000) e a poucos representantes marinhos ou de água doce - sendo, nos dois últimos casos, quase estritamente limitados a estudos com espécies de peixes (e.g., Alonzo \& Warner, 2000; Gage et al., 2004). Nesse aspecto, o presente trabalho contribui para o conhecimento a respeito dos mecanismos de competição espermática em invertebrados marinhos, uma área praticamente inexplorada, além de utilizar como objeto de estudo um grupo com características muito distintas dos táxons utilizados para elaboração dos modelos teóricos, e.g., cujos morfos apresentam sítios de deposição de espermatóforos distintos no interior do corpo da fêmea. Interessantemente, os resultados obtidos nesse trabalho com relação ao investimento gonadal em indivíduos dimórficos mostram que machos da família D. plei de fato enquadram-se nas premissas teóricas do modelo de "sneakers e guardas" de competição espermática (Parker, 1990). Machos sneakers apresentam maior investimento relativo em gônadas do que machos consorts, os quais por sua vez parecem investir mais em crescimento somático, resultado que corrobora a ideia de que machos sneakers, os quais apresentariam uma desvantagem comportamental em relação a machos dominantes, deveriam investir mais em gônadas como forma de compensar as pressões assimétricas da competição espermática (Parker, 1990). Com base nesses resultados, recomenda-se que estudos relacionados a investimento gonadal de machos dimórficos sejam 
executados para outras espécies da família Loliginidae, tais como Heterololigo bleekeri ${ }^{2}$, de forma a aprimorar o conhecimento a respeito de como as pressões relacionadas à competição espermática desigual entre machos sneakers e consorts influenciam a evolução do dimorfísmo intrassexual em lulas.

Um dos resultados mais interessantes do presente trabalho, apresentado no Capítulo 1, está relacionado à constatação de que machos sneakers produzem espermatóforos com uma quantidade descontinuamente menor de massa espermática do que machos consorts, resultado esse que, em um primeiro momento, parece contradizer os modelos teóricos de competição espermática apresentados no parágrafo anterior. No entanto, observações comportamentais realizadas ao longo da execução desse trabalho, somadas a relatos prévios para outras espécies de Loliginidae (Hanlon, 1998; Hanlon et al., 1997, 2002), conduziram à elaboração da hipótese inédita de fracionamento de produtos ejaculatórios em machos sneakers em lulas. De acordo com essa hipótese, a estratégia reprodutiva de machos sneakers estaria relacionada ao menor investimento espermático por fêmea (i.e., por cópula), o qual, consequentemente, permitiria a realização de número maior de cópulas, com o maior número de fêmeas possível, sem exaurir seu estoque espermático. Machos consorts, por sua vez, se beneficiariam de maior investimento em crescimento somático, associado à monopolização de fêmeas e vitórias em disputas com outros machos.

Ainda sob o contexto da competição espermática, as diferenças morfológicas encontradas entre estruturas reprodutivas (e.g., espermatóforos, espermatângios, espermatozoides) de machos sneakers e consorts, descritas no presente trabalho (Capítulos $1 \mathrm{e}$ 2), são de extrema relevância ao tema, pois evidenciam que a teoria da competição espermática não é suficiente para explicar todas as diferenças morfológicas encontradas nos produtos ejaculatórios entre os morfotipos. Fatores como a presença de dois sítios de deposição de espermatóforos e de fertilização, assim como a variação no intervalo entre cópulas e desova, parecem altamente associados às adaptações divergentes observadas nos produtos ejaculatórios de machos dimórficos. Dessa forma, é muito provável que pressões seletivas diferentes em machos sneakers e consorts influenciem a evolução e manutenção do dimorfismo intrassexual dentro da espécie, como previamente sugerido para o grupo (Iwata et al., 2011, 2014).

\footnotetext{
${ }^{2}$ Única espécie da família Loliginidae para a qual o dimorfismo intrassexual entre machos sneakers e consorts foi amplamente estudado até o momento.
} 
A caracterização do dimorfismo intrassexual, apresentada no Capítulo 2, evidenciou ainda que as diferenças morfológicas e funcionais entre espermatóforos de machos sneakers e consorts extrapolavam a questão da proporção de massa espermática (descrita no Capítulo 1), estendendo-se ao longo das três regiões do espermatóforo (i.e., aparato ejaculatório, corpo cimentante e massa espermática). Além disso, os resultados obtidos a partir de análises morfológicas, morfométricas e a partir de técnicas histológicas de espermatóforos intactos revelaram que diferenças na configuração dessa estrutura entre machos sneakers e consorts, principalmente quanto ao aparato ejaculatório e corpo cimentante, estavam profundamente interligadas às diferenças encontradas entre machos dimórficos durante a reação espermatofórica e na morfologia final do espermatângio, assim como ao padrão divergente de liberação de espermatozoides a partir de sua estrutura.

Apesar da existência de dimorfismo intrassexual ter sido explorada somente em lulas (e.g., Iwata \& Sakurai, 2007; presente trabalho), a adoção de táticas alternativas de reprodução em cefalópodes são de forma geral associadas a machos de tamanhos diferentes, tanto em lulas quanto em sépias, com machos menores exibindo comportamentos típicos de sneakers e machos maiores empregando táticas dominantes (e.g., Hanlon et al., 1997, 1999, 2002, 2005). No entanto, a hipótese de que a expressão desses fenótipos alternativos poderiam constituir uma mudança ontogenética, com alternância de um morfotipo para outro conforme o animal aumenta de tamanho ao longo da vida, nunca havia sido sugerida até o presente. Nesse contexto, dois dos aspectos mais inovadores do presente trabalho estão relacionados 1) à descrição de machos capazes de produzir espermatóforos com morfologia de sneakers e consorts, além de espermatóforos e espermatângios "em transição" entre ambos os morfotipos e 2) à abordagem da questão das diferenças de idade entre machos dimórficos, os quais, combinados, permitiram a proposição de uma hipótese ontogenética para transição entre morfotipos, algo totalmente original para o grupo.

Por fim, os resultados desse trabalho, com ênfase às descobertas relatadas no parágrafo anterior, são de extrema relevância para o estudo dos possíveis mecanismos responsáveis por influenciar ou até mesmo determinar a expressão de um ou outro morfo, uma área completamente inexplorada até o presente para cefalópodes. Futuros estudos na área devem investigar se a mudança ontogenética entre machos dimórficos é obrigatória, i.e., todos os indivíduos passariam pelas fases de sneaker e consort, ou facultativa, i.e., alguns indivíduos passariam por ambas as fases, enquanto outros adotariam somente a tática de consort. Além disso, diversos questionamentos a respeito dos gatilhos, tanto intrínsecos (e.g., tamanho do 
corpo) quanto extrínsecos (e.g., ambientais, demográficos), que influenciariam a transição de um fenótipo para outro, assim como quais as alterações morfológicas, fisiológicas e comportamentais que ocorrem no indivíduo ao longo da mudança entre morfos ainda são completamente desconhecidos. $\mathrm{O}$ aprofundamento do conhecimento desse fascinante fenômeno será de extrema relevância não somente para o conhecimento das táticas alternativas de reprodução em cefalópodes, mas para o amplo entendimento da complexidade dos mecanismos de expressão de fenótipos alternativos em animais. 


\section{Referências bibliográficas}

Aguiar, D. C.; Rossi-Wongtschowski, C. L. D. B. \& Perez, J. A. A. (2012) Validation of daily growth increments of statoliths of Brazilian squid Doryteuthis plei and D. sanpaulensis (Cephalopoda: Loliginidae). Bioikos, 26(1): 13-21.

Alcock, J. (1994) Post-insemination associations between males and females in insects: the mate-guarding hypothesis. Annual Review of Entomology, 39: 1-21.

Allcock, A. L.; Lindgren, A. \& Strugnell, J. M. (2015) The contribution of molecular data to our understanding of cephalopod evolution and systematics: a review. Journal of Natural History, 49: 1373-1421.

Alonzo, S. H.; Taborsky, M. \& Wirtz, P. (2000) Male alternative reproductive behaviors in a Mediterranean wrasse, Symphodus ocellatus: evidence from otoliths for multiple life-history pathways. Evolutionary Ecology Research, 2: 997-1007.

Alonzo, S. H. \& Warner, R. R. (2000) Allocation to mate guarding or increased sperm production in a Mediterranean wrasse. The American Naturalist, 156(3): 266-275.

Andersson, M. (1994) Sexual Selection. Princeton: Princeton University Press, 624p.

Andersson, M. \& Iwasa, Y. (1996) Sexual selection. Trends in Ecology \& Evolution, 11(2): 53-58.

Andersson, J.; Borg-Karlson, A. K. \& Wiklund, C. (2000) Sexual cooperation and conflict in butterflies: a male-transferred anti-aphrodisiac reduces harassment of recently mated females. Proceedings of the Royal Society of London B: Biological Sciences, 267: 12711275 .

Andersson, J.; Borg-Karlson, A. K. \& Wiklund, C. (2004) Sexual conflict and antiaphrodisiac titre in a polyandrous butterfly: male ejaculate tailoring and absence of female control. Proceedings of the Royal Society of London B: Biological Sciences, 271: 17651770 .

Andersson, M. \& Simmons, L. W. (2006) Sexual selection and mate choice. Trends in Ecology and Evolution, 21(6): 296-302.

Arkhipkin, A. I. (1997) Age and growth of the mesopelagic squid Ancistrocheirus lesuerii (Oegopsida: Ancistrocheiridae) from the central-east Atlantic based on statolith microstructure. Marine Biology, 129: 103-111.

Arkhipkin, A. I. (2005) Statoliths as 'black boxes' (life recorders) in squid. Marine and Freshwater Research, 56: 573-583. 
Arkhipkin, A. I. \& Bizkov, V. A. (2000) Role of the statolith in functioning of the acceleration receptor system in squids and sepioids. Journal of Zoology, 25: 31-55.

Arnold, J. M. (1962) Mating behavior and social structure in Loligo pealii. Biological Bulletin, 123(1): 53-57.

Aubin-Horth, N.; Bourque, J. F.; Daigle, G.; Hedger, R. \& Dodson, J. J. (2006) Longitudinal gradientes in threshold sizes for alternative male life history tactics in a population of Atlantic salmon (Salmo salar). Canadian Journal of Fisheries and Aquatic Sciences, 63: 2067-2075.

Austad, S. N. (1984) A classification of alternative reproductive behaviors and methods for field-testing ESS Models. American Zoologist, 24: 309-319.

Austin, C. R.; Lutwak-Mann, C. \& Mann, T. (1964) Spermatophores and spermatozoa of the squid Loligo pealii. Proceedings of the Royal Society of London B: Biological Sciences, 161: 143-152.

Ball, M. A. \& Parker, G. A. (1996) Sperm competition games: external fertilization and "adaptive" infertility. Journal of Theoretical Biology, 180: 141-150.

Ball, M. A. \& Parker, G. A. (1997) Sperm competition games: inter- and intra-species results of a continuous external fertilization model. Journal of Theoretical Biology, 186: 459-466.

Bancroft, J. D. \& Stevens, A. (1982) Theory and practice of histological techniques. London: Churchill Livingstone, 680p.

Barbieri, E.; Paster, B. J.; Hughes, D.; Zurek, L.; Moser, D.; Teske, A. \& Sogin, M. L. (2001) Phylogenetic characterization of epibiotic bacteria in the accessory nidamental gland and egg capsules of the squid Loligo pealei (Cephalopoda: Loliginidae). Environmental Microbiology, 3(3): 151-167.

Barcellos, D. D. (2014) Estatólitos da lula Doryteuthis plei e suas microestruturas para o estudo da idade e crescimento no litoral norte do Estado de São Paulo, Brasil. Dissertação (Mestrado em Oceanografia Biológica) - Instituto Oceanográfico, Universidade de São Paulo, São Paulo, 145p.

Bateman, A. J. (1948) Intrasexual Selection in Drosophila. Heredity, 2: 349-368.

Baum, D.; Laughton, R.; Armstrong, J. D. \& Metcalfe, N. B. (2004) Altitudinal variation in the relationship between growth and maturation rate in salmon parr. Journal of Animal Ecology, 73: 253-260.

Baur, B. (1998) Sperm Competition in Molluscs. In: Birkhead, T. R. \& Møller, A. P. (Eds.) Sperm Competition and Sexual Selection. San Diego: Academic Press, p. 255-305. 
Beamish, R. J. \& Fournier, D. A. (1981) Method for comparing the precision of a set of age determinations. Canadian Journal of Fisheries and Aquatic Sciences, 38(8): 982-983.

Bettencourt, V.; Coelho, L.; Andrade, J. P. \& Guerra, A. (1996) Age and growth of the squid Loligo vulgaris off the south coast of Portugal, using statolith analysis. Journal of Molluscan Studies, 62: 359-366.

Birkhead, T. R. (2010) How stupid not to have thought of that: post-copulatory sexual selection. Journal of Zoology, 281: 78-93.

Birkhead, T. R. \& Hunter, F. M. (1990) Mechanisms of sperm competition. Trends in Ecology and Evolution, 5(2): 48-52.

Birkhead, T. R. \& Møller, A. P. (1998) Sperm Competition and Sexual Selection. San Diego: Academic Press, 826p.

Birkhead, T. R. \& Pizzari, T. (2002) Postcopulatory sexual selection. Nature Reviews, 3: 262273.

Blackenhorn, W. U. (2005) Behavioral causes and consequences of sexual size dimorphism. Ethology, 111: 977-1016.

Boyle, P. R. (1990) Cephalopod biology in the fisheries context. Fisheries Research, 8: 303321.

Boyle, P. R. \& Boletzky, S. V. (1996) Cephalopod populations: definition and dynamics. Philosophical Transactions of the Royal Society B: Biological Sciences, 351: 985-1002.

Boyle, P. R. \& Rodhouse, P. G. (2005) Cephalopods: Ecology and Fisheries. Oxford: Blackwell, 452 p.

Briskie, J. V.; Montgomerie, R. \& Birkhead, T. R. (1997) The evolution of sperm size in birds. Evolution, 51(3): 937-945.

Brockmann, H. J. (2001) The evolution of alternative strategies and tactics. Advances in the Study of Behavior, 30: 1-51.

Buresch, K. C.; Maxwell, M. R.; Cox, M. R. \& Hanlon, R. T. (2009) Temporal dynamics of mating and paternity in the squid Loligo pealeii. Marine Ecology Progress Series, 387: $197-$ 203.

Buresch, K. M.; Hanlon, R. T.; Maxwell, M. R. \& Ring, S. (2001) Microsatellite DNA markers indicate a high frequency of multiple paternity within individual field-collected egg capsules of the squid Loligo pealeii. Marine Ecology Progress Series, 210: 161-165.

Buzatto, B. A.; Requena, G. S.; Lourenço, R. S.; Munguía-Steyer, R. \& Machado, G. (2011) Conditional male dimorphism and alternative reproductive tactics in a Neotropical arachnid (Opiliones). Evolutionary Ecology, 25: 331-349. 
Chang, W. Y. B. (1982) A statistical method for evaluating the reproducibility of age determination. Canadian Journal of Fisheries Aquatic Sciences, 39(8): 1208-1210.

Cigliano, J. A. (1995) Assessment of the mating history of female pygmy octopuses and a possible sperm competition mechanism. Animal Behavior, 49: 849-851.

Clarke, M. R. (1966) A review of the systematics and ecology of oceanic squids. Advances in Marine Biology, 4: 91-300.

Cook, P. A. \& Wedell, N. (1999) Non-fertile sperm delay female remating. Nature, 397: 486.

Correa, C.; Baeza, J. A.; Hinojosa, I. A. \& Thiel, M. (2003) Male dominance hierarchy and mating tactics in the rock shrimp Rhynchocinetes typus (Decapoda: Caridea). Journal of Crustacean Biology, 23(1): 33-45.

Darwin, C. (1871) The descent of man and selection in relation to sex. London: John Murray, $693 p$.

delBarco-Trillo, J. (2011) Adjustment of sperm allocation under high risk of sperm competition across taxa: a meta-analysis. Journal of Evolutionary Biology, 24: 1706-1714.

DiMarco, F. P. \& Hanlon, R. T. (1997) Agonistic behavior in the squid Loligo plei (Loliginidae, Teuthoidea): Fighting tactics and the effects of size and resource value. Ethology, 103: 89-108.

Dominey, W. J. (1980) Female mimicry in male bluegill sunfish - a genetic polymorphism? Nature, 284: 546-548.

Dominey, W. J. (1984) Alternative Mating Tactics and Evolutionarily Stable Strategies. American Zoologist, 24: 385-396.

Drew, G. A. (1911) Sexual activities of the squid, Loligo pealii. I. Copulation, egg-laying and fertilization. Journal of Morphology, 22: 327-359.

Drew, G. A. (1919) Sexual activities of the squid, Loligo pealii. II. The spermatophore; its structure, ejaculation and formation. Journal of Morphology, 32: 379-435.

Durholtz, M. D.; Lipinski, M. R. \& Field, J. G. (2002) Laboratory validation of periodicity of incrementation in statoliths of the South African chokka squid Loligo vulgaris reynaudii (d'Orbigny, 1845): a reevaluation. Journal of Experimental Marine Biology and Ecology, 279: 41-59.

Eberhard, W. G. (1982) Beetle horn dimorphism: making the best of a bad lot. The American Naturalist, 119: 420-426.

Eberhard, W. G. (1985) Sexual selection and animal genitalia. Cambridge: Harvard University Press, 224p. 
Eberhard, W. G. (1996) Female control: Sexual selection by cryptic female choice. New Jersey: Princeton University Press, 501p.

Eberhard, W. G. \& Gutiérrez, E. E. (1991) Male dimorphisms in beetles and earwigs and the question of developmental constraints. Evolution, 45(1): 18-28.

Emlen, D. J. \& Nijhout, H. F. (2000) The development and evolution of exaggerated morphologies in insects. Annual Review of Entomology, 45(1): 661-708.

Emlen, S. T. \& Oring, L. W. (1977) Ecology, sexual selection, and the evolution of mating systems. Science, 197: 215-223.

Fairbairn, D. J. (1997) Allometry for sexual size dimorphism: pattern and process in the coevolution of body size in males and females. Annual Review of Ecology, Evolution, and Systematics, 28: 659-687.

Forstmeier, W.; Nakagawa, S.; Griffith, S. C. \& Kempenaers, B. (2014) female extra-pair mating: adaptation of genetic constraint? Trends in Ecology \& Evolution, 29(8): 456-464.

Fryer, T.; Cannings, C. \& Vickers, G. T. (1999) Sperm Competition. II - Post-copulatory guarding. Journal of Theoretical Biology, 197: 343-360.

Gadgil, M. (1972) Male dimorphism as a consequence of sexual selection. The American Naturalist, 106(951): 574-580.

Gage, M. J. G. (1994) Associations between body size, mating pattern, testis size and sperm lengths across butterflies. Proceedings of the Royal Society of London B: Biological Sciences, 258: 247-254.

Gage, A. R. \& Barnard, C. J. (1996) Male crickets increase sperm number in relation to competition and female size. Behavioral Ecology and Sociobiology, 38: 349-353.

Gage, M. J. G. \& Freckleton, R. P. (2003) Relative testis size and sperm morphometry across mammals: no evidence for an association between sperm competition and sperm length. Proceedings of the Royal Society of London B: Biological Sciences, 270: 625-632.

Gage, M. J. G. \& Morrow, E. H. (2003) Experimental evidence for the evolution of numerous, tiny sperm via sperm competition. Current Biology, 13: 754-757.

Gage, M. J. G.; Stockley, P. \& Parker, G. A. (1995) Effects of alternative male mating strategies on characteristics of sperm production in the Atlantic salmon (Salmo salar): theoretical and empirical investigations. Philosophical Transactions of the Royal Society B: Biological Sciences, 350: 391-399.

Gage, M. J. G.; Macfarlane, C. P.; Yeates, S.; Ward, R. G.; Searle, J. B. \& Parker, G. A. (2004) Spermatozoal traits and sperm competition in Atlantic salmon: relative sperm velocity is the primary determinant of fertilization success. Current Biology, 14: 44-47. 
García-González, F. \& Gomendio, M. (2004) Adjustment of copula duration and ejaculate size according to the risk of sperm competition in the golden egg bug (Phyllomorpha laciniata). Behavioral Ecology, 15(1): 23-30.

Gomendio, M. \& Roldan, E. R. S. (1991) Sperm competition influences sperm size in mammals. Proceedings of the Royal Society of London B: Biological Sciences, 243: 181185.

Gross, M. R. (1985) Disruptive selection for alternative life histories in salmon. Nature, 313: 47-48.

Gross, M. R. (1991) Salmon breeding behavior and life history evolution in changing environments. Ecology, 72(4): 1180-1186.

Gross, M. R. (1996) Alternative reproductive strategies and tactics: diversity within sexes. Trends in Ecology \& Evolution, 11(2): 92-98.

Gross, M. R. \& Repka, J. (1998) Stability with inheritance in the conditional strategy. Journal of Theoretical Biology, 192: 445-453.

Hall, K. C. \& Hanlon, R. T. (2002) Principal features of the mating system of a large spawning aggregation of the giant Australian cuttlefish Sepia apama (Mollusca: Cephalopoda). Marine Biology, 140: 533-545.

Halliday, T. M. \& Tejedo, M. (1995) Intrasexual selection and alternative mating behavior. In: Heatwole, H. \& Sullivan, B. K. (Eds.). Amphibian Biology, Vol. 2. Chipping Norton: Surrey Beatty and Sons. p.469-517.

Hanlon, R. T. (1996) Evolutionary games that squids play: fighting, courting, sneaking, and mating behaviors used for sexual selection in Loligo pealei. Biological Bulletin, 191: 309310 .

Hanlon, R. T. (1998) Mating systems and sexual selection in the squid Loligo: How might commercial fishing on spawning squids affect them? California Cooperative Oceanic Fisheries Investigations Reports, 39: 92-100.

Hanlon, R. T. \& Messenger, J. B. (1996) Cephalopod Behaviour. Cambridge: Cambridge University Press, 232 p.

Hanlon, R. T.; Maxwell, M. R. \& Shashar, N. (1997) Behavioral dynamics that would lead to multiple paternity within egg capsules of the squid Loligo pealei. Biological Bulletin, 193: 212-214.

Hanlon, R. T.; Ament, S. A. \& Gabr, H. (1999) Behavioral aspects of sperm competition in cuttlefish, Sepia officinalis (Sepioidea: Cephalopoda). Marine Biology, 134: 719-728. 
Hanlon, R. T.; Smale, M. J. \& Sauer, W. H. H. (2002) The mating system of the squid Loligo vulgaris reynaudii (Cephalopoda, Mollusca) off South Africa: Fighting, guarding, sneaking, mating and egg laying behavior. Bulletin of Marine Science, 71(1): 331-345.

Hanlon, R. T.; Naud, M-J.; Shaw, P. W. \& Havenhand, J. N. (2005) Transient sexual mimicry leads to fertilization. Nature, 433: 212.

Harman, R. F.; Young, R. E.; Reid, S. B.; Mangold, K. M.; Suzuki, T. \& Hixon, R. F. (1989) Evidence of multiple spawning in the tropical oceanic squid Stenoteuthis oualaniensis (Teuthoidea: Ommastrephidae). Marine Biology, 101: 513-519.

Hazel, W. N.; Smock, R. \& Johnson, M. D. (1990) A polygenic model for the evolution and maintenance of conditional strategies. Proceedings of the Royal Society of London B: Biological Sciences, 242: 181-187.

Hellriegel, B. \& Blackenhorn, W. U. (2002) Environmental influences on the gametic investment of yellow dung fly males. Evolutionary Ecology, 16: 505-522.

Helversen, D. V. \& Helversen, O. V. (1991) Pre-mating sperm removal in the bushcricket Metaplastes ornatus Ramme 1931 (Orthoptera, Tettigonoidea, Phaneropteridae). Behavioral Ecology and Sociobiology, 28: 391-396.

Hirohashi, N. \& Iwata, Y. (2013) The different types of sperm morphology and behavior within a single species: Why do sperm of squid sneaker males form a cluster? Communicative \& Integrative Biology, 6(6): e26729 1-3.

Hirohashi, N.; Alvarez, L.; Shiba, K.; Fujiwara, E.; Iwata, Y.; Mohri, T.; Inaba, K.; Chiba, K.; Ochi, H.; Supuran, C. T.; Kotzur, N.; Kakiuchi, Y.; Kaupp, U. B. \& Baba, S. A. (2013) Sperm from sneaker male squids exhibit chemotactic swarming to $\mathrm{CO}_{2}$. Current Biology, 23(9): $1-7$.

Hosken, D. J. (1997) Sperm competition in bats. Proceedings of the Royal Society of London B: Biological Sciences, 264: 385-392.

Hosken, D. J. \& Ward, P. I. (2001) Experimental evidence for testis size evolution via sperm competition. Ecology Letters, 4: 10-13.

Hosken, D. J.; Garner, T. W. J. \& Ward, P. I. (2001) Sexual conflict selects for male and female reproductive characters. Current Biology, 11: 489-493.

Hoving, H. J. T. \& Lipinski, M. R. (2015) Observations on age and reproduction of the oceanic squid Ancistrocheirus lesueurii (d'Orbigny, 1842) (Cephalopoda: Ancistrocheiridae). Journal of Natural History, 49: 1318-1325. 
Hoving, H. J. T.; Nauwelaerts, S.; Van Genne, B.; Stamhuis, E. J. \& Zumholz, K. (2009) Spermatophore implantation in Rossia moelleri Steenstrup, 1856 (Sepiolidae; Cephalopoda). Journal of Experimental Marine Biology and Ecology, 372: 75-81.

Hoving, H. J. T.; Perez, J. A. A.; Bolstad, K. S. R.; Braid, H. E.; Evans, A. B.; Fuchs, D.; Judkins, H.; Kelly, J. T.; Marian, J. E. A. R.; Nakajima, R.; Piatkowski, U.; Reid, A.; Vecchione, M. \& Xavier. J. C. C. (2014) The Study of Deep-Sea Cephalopods. In: Vidal, E. A. G. (Ed.) Advances in Marine Biology, v. 67. Oxford: United Kingdom, p. 235-359.

Humanson, G. L. (1962) Animal tissue techniques. San Francisco: W. H. Freeman and Company, 468p.

Hunt, J. \& Simmons, L. W. (2000) Maternal and paternal effects on offspring phenotype in the dung beetle Onthophagus taurus. Evolution, 54(3): 936-941.

Hunt, J. \& Simmons, L. W. (2001) Status-dependent selection in the dimorphic beetle Onthophagus taurus. Proceedings of the Royal Society of London B: Biological Sciences, 268: 2409-2414.

Immler, S.; Pitnick, S.; Parker, G. A.; Durrant, K. L.; Lupold, S.; Calhim, S. \& Birkhead, T. R. (2011) Resolving variation in the reproductive trade-off between sperm size and number. Proceedings of the National Academy of Sciences, 108(13): 5325-5330.

Ingleby, F. C.; Lewis, Z. \& Wedell, N. (2010) Level of sperm competition promotes evolution of male ejaculate allocation patterns in a moth. Animal Behaviour, 80: 37-43.

Iwata, Y. \& Sakurai, Y. (2007) Threshold dimorphism in ejaculate characteristics in the squid Loligo bleekeri. Marine Ecology Progress Series, 345: 141-146.

Iwata, Y.; Munehara, H. \& Sakurai, Y. (2005) Dependence of paternity rates on alternative reproductive behaviors in the squid Loligo bleekeri. Marine Ecology Progress Series, 298: 219-228.

Iwata, Y.; Shaw, P.; Fujiwara, E.; Shiba, K.; Kakiuchi, Y. \& Hirohashi, N. (2011) Why small males have big sperm: dimorphic squid sperm linked to alternative mating behaviours. $B M C$ Evolutionary Biology, 11: 1-9.

Iwata, Y.; Sakurai, Y.; Shaw, P. (2014) Dimorphic sperm-transfer strategies and alternative mating tactics in loliginid squid. Journal of Molluscan Studies, 81(1): 147-151.

Jackson, G. D. (1989a) Age and growth of the tropical nearshore loliginid squid Sepioteuthis lessoniana determined from statolith growth-ring analysis. Fishery Bulletin, 88(1): 113-118.

Jackson, G. D. (1989b) The use of statolith microstructures to analyze life-history events in the small tropical cephalopod Idiosepius pygmaeus. Fishery Bulletin, 87(2): 265-272. 
Jackson, G. D. \& Forsythe, J. W. (2002) Statolith age validation and growth of Loligo plei (Cephalopoda: Loliginidae) in the north-west Gulf of Mexico during spring/summer. Journal of Marine Biological Association of the United Kingdom, 82(4): 677-678.

Jackson, G.D. \& Moltschaniwskyj, N. A. (1999). Analysis of precision in statolith derived age estimates of the tropical squid Photololigo (Cephalopoda: Loliginidae). ICES Journal of Marine Science, 56: 221-227.

Jackson, G. D.; Forsythe, J. W.; Hixon, R. F. \& Hanlon, R. T. (1997) Age, growth, and maturation of Lolliguncula brevis (Cephalopoda: Loliginidae) in the northwestern Gulf of Mexico with a comparison of length-frequency versus statolith age analysis. Canadian Journal of Fisheries and Aquatic Sciences, 54: 2907-2919.

Jereb, P. \& Roper, C. F. E. (2005) Cephalopods of the world. An annotated and illustrated catalogue of cephalopod species known to date. Volume 2. Myopsid and Oegopsid squids. FAO Species Catalogue for Fishery Purposes. $N^{0}$ 4, Vol. 2. Rome, FAO. 649 p.

Kelly, C. D. \& Jennions, M. D. (2011) Sexual selection and sperm quantity: meta-analysis of strategic ejaculation. Biological Reviews, 86: 863-884.

Kristensen, T. K. (1980) Periodical growth rings in cephalopod statoliths. Dana, 1: 39-51.

Kuijper, B.; Pen, I. \& Weissing, F. J. (2012) A Guide to Sexual Selection Theory. Annual Review of Ecology, Evolution, and Systematics, 43: 287-311.

Kvarnemo, C. \& Simmons, L. W. (2013) Polyandry as a mediator of sexual selection before and after mating. Philosophical Transactions of the Royal Society B: Biological Sciences, 368: $1-16$.

LaMunyon, C. W. \& Ward, S. (1998) Larger sperm outcompete smaller sperm in the nematode Caenorhabditis elegans. Proceedings of the Royal Society of London B: Biological Sciences, 265: 1997-2002.

LaMunyon, C. W. \& Ward, S. (1999) Evolution of sperm size in nematodes: sperm competition favours larger sperm. Proceedings of the Royal Society of London B: Biological Sciences, 266: 263-267.

Lande, R. (1980) Sexual dimorphism, sexual selection, and adaptation in polygenic characters. Evolution, 34(2): 292-305.

Lank, D. B.; Smith, C. M.; Hanotte, O.; Burke, T. \& Cooke, F. (1995) Genetic polymorphism for alternative mating behavior in lekking male ruff Philomachus pugnax. Nature, 78: 59-62.

Lipinski, M. R.; Durholtz, M. D. \& Underhill, L. G. (1998) Field validation of age reading from the statoliths of chokka squid (Loligo vulgaris reynaudii d'Orbigny, 1985) and an assessment of associated errors. ICES Journal of Marine Science, 55: 240-257. 
Lupold, S.; Linz, G. M.; Rivers, J. W.; Westneat, D. F. \& Birkhead, T. R. (2008) Sperm competition selects beyond relative testes size in birds. Evolution, 63(2): 391-402.

Mann, T. (1984) Spermatophores. Development, structure, biochemical attributes and role in transfer of spermatozoa. Zoophysiology, v. 15. Berlin: Springer-Verlag, 217 p.

Mann, T.; Martin, A. W.; Thiersch, J. B. (1970) Male reproductive tract, spermatophores and spermatophoric reaction in the giant octopus of the North Pacific, Octopus dofleini martini. Proceedings of the Royal Society of London B: Biological Sciences, 175: 31-61.

Manning, J. T. (1985) Choosy females and correlates of male age. Journal of Theoretical Biology, 116: 349-354.

Marian, J. E. A. R. (2012a) Spermatophoric reaction reappraised: novel insights into the functioning of the loliginid spermatophore based on Doryteuthis plei (Mollusca: Cephalopoda). Journal of Morphology, 273: 248-278.

Marian, J. E. A. R. (2012b) A model to explain spermatophore implantation in cephalopods (Mollusca: Cephalopoda) and a discussion on its evolutionary origins and significance. Biological Journal of the Linnean Society, 105: 711-726.

Marian, J. E. A. R. (2015) Evolution of spermatophore transfer mechanisms in cephalopods. Journal of Natural History, 49: 1423-1455.

Marian, J. E. A. R. \& Domaneschi, O. (2012) Unraveling the structure of squids' spermatophores: a combined approach based on Doryteuthis plei (Blainville, 1823) (Cephalopoda: Loliginidae). Acta Zoologica, 93: 281-307.

Martin, O. Y. \& Hosken, D. J. (2002) Strategic ejaculation in the common dung fly Sepsis cynipsea. Animal Behaviour, 63: 541-546.

Matsumoto, K. \& Suzuki, N. (1992) Effectiveness of the mating plug in Atrophaneura alcinous (Lepidoptera: Papilionidae). Behavioral Ecology and Sociobiology, 30: 157-163.

Maxwell, M. R. \& Hanlon, R. T. (2000) Female reproductive output in the squid Loligo pealeii: multiple egg clutches and implications for a spawning strategy. Marine Ecology Progress Series, 199: 159-170.

Maxwell, M. R.; Macy, W. K.; Odate, S. \& Hanlon, R. T. (1998) Evidence for multiple spawning by squids (Loligo pealei) in captivity. Biological Bulletin, 195: 225-226.

Mazzoldi, C.; Scaggiante, M.; Ambrosin, E.; Rasotto, M. B. (2000) Mating system and alternative male mating tactics in the grass goby Zosterisessor ophiocephalus (Teleostei: Gobiidae). Marine Biology, 137: 1041-1048.

Moczek, A. P. \& Nijhout, H. F. (2003) Rapid evolution of a polyphenic threshold. Evolution \& Development, 5(3): 259-268. 
Moczek, A. P.; Hunt, J.; Emlen, D. J. \& Simmons, L. W. (2002) Threshold evolution in exotic populations of a polyphenic beetle. Evolutionary Ecology Research, 4: 587-601.

Møller, A. P. (1988a) Ejaculate quality, testes size and sperm competition in primates. Journal of Human Evolution, 17: 479-488.

Møller, A. P. (1988b) Testes size, ejaculate quality and sperm competition in birds. Biological Journal of the Linnean Society, 33: 273-283.

Møller, A. P. (1989) Ejaculate quality, testes size and sperm production in mammals. Functional Ecology, 3: 91-96.

Møller, A. P. \& Briskie, J. V. (1995) Extra-pair paternity, sperm competition and the evolution of testis size in birds. Behavioral Ecology and Sociobiology, 36: 357-365.

Moltschaniwskyj, N. A. (1995) Multiple spawning in the tropical squid Photololigo sp.: what is the cost in somatic growth? Marine Biology, 124: 127-135.

Moltschaniwskyj, N. A.; Hall, K.; Lipinski, M. R.; Marian, J. E. A. R.; Nishiguchi, M.; Sakai, M.; Shulman, D. J.; Sinclair, B.; Sinn, D. L.; Staudinger, M.; Van Gelderen, R.; Villanueva, R. \& Warnke, K. (2007) Ethical and welfare considerations when using cephalopods as experimental animals. Reviews in Fish Biology and Fisheries, 17: 455-476.

Montoto, L. G.; Magaña, C.; Tourmente, M.; Martín-Coello, J.; Crespo, C.; Luque-Larena, J. J.; Gomendio, M. \& Roldan, E. R. S. (2011) Sperm competition, sperm numbers and sperm quality in muroid rodents. PLoS ONE, 6(3): 1-10.

Morrow, E. H. \& Gage, M. J. G. (2000) The evolution of sperm length in moths. Proceedings of the Royal Society of London B: Biological Sciences, 267: 307-313.

Nakamura, Y. \& Sakurai, Y. (1991) Validation of daily growth increments in statoliths of japanese common squid Todarodes pacificus. Nippon Suisan Gakkaishi, 57(11): 2007-2011.

Natsukari, Y.; Nakanose, T. \& Oda, K. (1988) Age and growth of loliginid squid Photololigo edulis (Hoyle, 1885). Journal of Experimental Marine Biology and Ecology, 116: 177-190.

Naud, M-J; Sauer, W. H. H.; McKeown, N. J. \& Shaw, P.W. (2016) Multiple mating, paternity and complex fertilisation patterns in the chokka squid Loligo reynaudii. PLoS ONE, 11(2): e0146995 1-11.

Naud, M-J. \& Havenhand, J. N. (2006). Sperm motility and longevity in the giant cuttlefish, Sepia apama (Mollusca: Cephalopoda). Marine Biology, 148: 559-566.

Naud, M-J.; Hanlon, R. T.; Hall, K. C.; Shaw, P. W. \& Havenhand, J. N. (2004) Behavioural and genetic assessment of reproductive success in a spawning aggregation of the Australin giant cuttlefish, Sepia apama. Animal Behaviour, 67: 1043-1050. 
Naud, M-J.; Shaw, P.W.; Hanlon, R. T. \& Havenhand, J. N. (2005) Evidence for biased use of sperm sources in wild female giant cuttlefish (Sepia apama). Proceedings of the Royal Society B: Biological Sciences, 272: 1047-1051.

Nesis, K. N. (1995) Mating, spawning, and death in oceanic cephalopods: a review. Ruthenica, 6(1): 23-64.

Nixon, M. \& Young, J.Z. (2003) The brains and lives of Cephalopods. Oxford: Clarendon Press, 408p.

Oliveira, R. F., Taborsky, M. \& Brockmann, H. J. (2008) Alternative Reproductive Tactics: An Integrative Approach. Cambridge: Cambridge University Press, 519 p.

Oppliger, A.; Hosken, D. J. \& Ribi, G. (1998) Snail sperm producation characteristicsw vary with sperm competition risk. Proceedings of the Royal Society of London B: Biological Sciences, 265: 1527-1534.

Parker, G. A. (1970) Sperm competition and its evolutionary consequences in the insects. Biological Reviews, 45: 525-567.

Parker, G. A. (1974) Courtship persistence and female-guarding as male time investment strategies. Behaviour, 48(1): 157-183.

Parker, G. A. (1982) Why are there so many tiny sperm? Sperm competition and the maintenance of two sexes. Journal of Theoretical Biology, 96: 281-294.

Parker, G. A. (1984) Sperm competition and the evolution of animal mating strategies. In: Smith, R. L. (Ed). Sperm competition and the evolution of animal mating systems. New York: Academic Press, p.01-60.

Parker, G. A. (1990a) Sperm competition games: raffles and roles. Proceedings of the Royal Society of London B: Biological Sciences, 242: 120-126.

Parker, G. A. (1990b) Sperm competition games: sneaks and extra-pair copulations. Proceedings of the Royal Society of London B: Biological Sciences, 242: 127-133.

Parker, G. A. (1993) Sperm competition games: sperm size and sperm number under adult control. Proceedings of the Royal Society of London B: Biological Sciences, 253: 245-254.

Parker, G. A. (1998) Sperm competition and the evolution of ejaculates: towards a theory base. In: Birkhead, T. R. \& Møller, A. P. (Eds.) Sperm Competition and Sexual Selection. San Diego: Academic Press, p. 03-54.

Parker, G. A. \& Ball, M. A. (2005) Sperm competition, mating rate and the evolution of testis and ejaculate sizes: a population model. Biology Letters, 1: 235-238.

Parker, G. A. \& Pizzari, T. (2010) Sperm competition and ejaculate economics. Biological Reviews, 85: 897-934. 
Parker, G. A.; Simmons, L. W. \& Kirk, H. (1990) Analysing sperm competition data: simple models for predicting mechanisms. Behavioral Ecology and Sociobiology, 27: 55-65.

Parker, G. A.; Ball, M. A.; Stockley, P. \& Gage, M. J. G. (1996) Sperm competition games: individual assessment of sperm competition intensity by group spawners. Proceedings of the Royal Society of London B: Biological Sciences, 263: 1291-1297.

Parker, G. A.; Ball, M. A.; Stockley, P. \& Gage, J. G. (1997) Sperm competition games: a prospective analysis of risk assessment. Proceedings of the Royal Society of London B: Biological Sciences, 264: 1793-1802.

Parker, G. A.; Lessells, C. M. \& Simmons, L. W. (2013) Sperm competition games: a general model for precopulatory male-male competition. Evolution, 67(1): 95-109.

Pearse, A. G. E. (1985) Histochemistry, theoretical and applied. Vol. 2: Analytical technology. London: Churchill Livingstone, 624p.

Perez, J. A. A.; Aguiar, D. C. \& Oliveira, U. C. (2002) Biology and population dynamics of the long-finned squid Loligo plei (Cephalopoda: Loliginidae) in southern Brazilian waters. Fisheries Research, 58: 267-279.

Perez, J. A. A.; Aguiar, D. C. \& Santos, J. A. T. (2006) Gladius and statolith as tools for age and growth studies of the squid Loligo plei (Teuthida: Loliginidae) off Southern Brazil. Brazilian Archives of Biology and Technology, 49(5): 747-755.

Petrie, M. \& Kempenaers, B. (1998) Extra-pair paternity in birds: explaining variation between species and populations. Trends in Ecology \& Evolution, 13(2): 52-58.

Pitcher, T. E.; Dunn, P. O. \& Whittingham, L. A. (2005) Sperm competition and the evolution of testes size in birds. Journal of Evolutionary Biology, 18: 557-567.

Pitnick, S.; Miller, G. T.; Reagan, J. \& Holland, B. (2001) Males' evolutionary responses to experimental removal of sexual selection. Proceedings of the Royal Society of London B: Biological Sciences, 268: 1071-1080.

Radwan, J. (1995) Male morph determination in two species of acarid mites. Heredity, 74: $669-673$.

Radwan, J. (2003) Heritability of male morph in the bulb mite, Rhizoglyphus robini (Astigmata, Acaridae). Experimental and Applied Acarology, 29: 109-114.

Repka, J \& Gross, M. R. (1995) The evolutionarily stable strategy under individual condition and tactic frequency. Journal of Theoretical Biology, 176: 27-31.

Ridley, M. (1993) Evolution. Boston: Blackwell Scientific Publications, 670p. 
Rocha, F. \& Guerra, A. (1996) Signs of an extended and intermittent terminal spawning in the squids Loligo vulgaris Lamarck and Loligo forbesi Steenstrup (Cephalopoda: Loliginidae). Journal of Experimental Marine Biology and Ecology, 207: 177-189.

Rocha, F. \& Guerra, A. (1999) Age and growth of two sympatric squid Loligo vulgaris and Loligo forbesi, in Galician waters (north-west Spain). Journal of the Marine Biological Association of the United Kingdom, 79: 697-707.

Rocha, F.; Guerra, A. \& Gonzalez, A. F. (2001) A review of reproductive strategies in cephalopods. Biological Reviews, 76: 291-304.

Rodhouse, P. G. (1998) Physiological progenesis in cephalopod molluscs. Biological Bulletin, 195: 17-20.

Rodhouse, P. G. \& Hatfield, E. M. C. (1990) Age determination in squid using statolith growth increments. Fisheries Research, 8: 323-334.

Roff, D. A. (1996) The evolution of threshold traits in animals. The Quarterly Review of Biology, 71(1): 3-35.

Roff, D. A. (2011) Alternative strategies: the evolution of switch points. Current Biology, 21(8): R285-R287.

Rudolfsen, G.; Figenschou, L.; Folstad, I.; Tveiten, H. \& Figenschou, M. (2006) Rapid adjustments of sperm characteristics in relation to social status. Proceedings of the Royal Society of London B: Biological Sciences, 273: 325-332.

Ryan, M. J.; Pease, C. M. \& Morris, M. R. (1992) A genetic polymorphism in the swordtail Xiphophorus nigrensis: testing the prediction of equal fitnesses. The American Naturalist, 139(1): 21-31.

Sato, N.; Kasugai, T. \& Munehara, H. (2013) Sperm transfer or spermatangia removal: postcopulatory behavior of picking up spermatangium by female Japanese pygmy squid. Marine Biology, 160: 553-561.

Saunders, W. B. (1984) Nautilus growth and longevity: evidence from marked and recaptured animals. Science, 224: 990-992.

Schwarz, R. \& Perez, J. A. A. (2010) Growth model identification of short-finned squid Illex argentinus (Cephalopoda: Ommastrephidae) off southern Brazil using statoliths. Fisheries Research, 106: 177-184.

Shashar, N. \& Hanlon, R. T. (2013) Spawning behavior dynamics at communal egg beds in the squid Doryteuthis (Loligo) pealeii. Journal of Experimental Marine Biology and Ecology, 447: 65-74. 
Shaw, P. W. \& Sauer, W. H. H. (2004) Multiple paternity and complex fertilisation dynamics in the squid Loligo vulgaris reynaudii. Marine Ecology Progress Series, 270: 173-179.

Shuster, S. M. (2009) Sexual selection and mating systems. Proceedings of the National Academy of Sciences, 106: 10009-10016.

Shuster, S. M. \& Wade, M. J. (1991) Equal mating success among male reproductive strategies in a marine isopod. Nature, 350: 608-610.

Shuster, S. M. \& Wade, M. J. (2003) Mating systems and strategies. Princeton: Princeton University Press, 552p.

Shuster, S. M.; Briggs, W. R. \& Dennis, P. A. (2013) How multiple mating by females affects sexual selection. Philosophical Transactions of the Royal Society B: Biological Sciences, 368: $1-27$.

Simmons, L. W. (2001) Sperm competition and its evolutionary consequences in the insects. Princeton: Princeton University Press. 434 p.

Simmons, L. W. (2014) Sperm competition. In: Shuker, D. M. \& Simmons, L. W. (Eds.) The evolution of insect mating systems. Oxford: Oxford University Press, p. 181-203.

Simmons, L. W. \& García-González, F. (2008) Evolutionary reduction in testes size and competitive fertilization success in response to the experimental removal of sexual selection in dung beetles. Evolution, 62(10): 2580-2591.

Simmons, L. W. \& Tomkins, J. L. (1996) Sexual selection and the allometry of earwig forceps. Evolutionary Ecology, 10: 97-104.

Simmons, L. W.; Tomkins, J. L. \& Hunt, J. (1999) Sperm competition games played by dimorphic male beetles. Proceedings of the Royal Society of London B: Biological Sciences, 266: 145.150 .

Simmons, L. W.; Emlen, D. J. \& Tomkins, J. L. (2007) Sperm competition games between sneakers and guards: a comparative analysis using dimorphic male beetles. Evolution, 61(11): 2684-2692.

Sinervo, B. \& Lively, C. M. (1996) The rock-paper-scissors game and the evolution of alternative male strategies. Nature, 380: 240-243.

Smallegange, I. M. (2011) Complex environmental effects on the expression of alternative reproductive phenotypes in the bulb mite. Evolutionary Ecology, 25: 857-873.

Smallegange, I. M. \& Johansson, J. (2014) Life-history differences favor evolution of male dimorphism in competitive games. The American Naturalist, 183(2): 188-198.

Snook, R. R. (2005) Sperm in competition: not playing by the number. Trends in Ecology and Evolution, 20(1): 46-53. 
Spratt, J. D. (1979) Age and growth of the market squid, Loligo opalescens Berry, from statoliths. California Cooperative Oceanic Fisheries Investigations Reports, 20: 58-64.

Stockley, P. (1997) Sexual conflict resulting from adaptations to sperm competition. Trends in Ecology and Evolution, 12(4): 154-159.

Stockley, P. \& Purvis, A. (1993) Sperm competition in mammals: a comparative study of male roles and relative investment in sperm production. Functional Ecology, 7: 560-570.

Stockley, P. \& Seal, N. J. (2001) Plasticity in reproductive effort of male dung flies (Scatophaga stercoraria) as a response to larval density. Functional Ecology, 15: 96-102.

Stockley, P.; Gage, M. J. G.; Parker, G. A. \& Møller, A. P. (1997) Sperm competition in fishes: the evolution of testis size and ejaculate characteristics. The American Naturalist, 149(5): 933-954.

Strugnell, J.; Norman, M.; Jackson, J.; Drummond, A. J. \& Cooper, A. (2005) Molecular phylogeny of coleoid cephalopods (Mollusca: Cephalopoda) using a multigene approach: the effect of data partitioning on resolving phylogenies in a Bayesin framework. Molecular Phylogenetics and Evolution, 37: 426-441.

Taborsky, M. (1994) Sneakers, satellites, and helpers: parasitic and cooperative behavior in fish reproduction. Advances in the study of behavior, 23: 1-100.

Taborsky, M. (1998) Sperm competition in fish: 'bourgeois' males and parasitic spawning. Trends in Ecology \& Evolution, 13(6): 222-227.

Taborsky, M.; Oliveira, R. F. \& Brockmann, J. (2008). The evolution of alternative reproductive tactics: concepts and questions. In: Oliveira, R. F.; Taborsky, M. \& Brockmann, H. J. (Eds.). Alternative Reproductive Tactics: An Integrative Approach. Cambridge: Cambridge University Press, p.1-21.

Takahama, H.; Kinoshita, T.; Sato, M. \& Sasaki, F. (1991) Fine structure of the spermatophores and their ejaculated forms, sperm reservoirs, of the Japanese common squid, Todarodes pacificus. Journal of Morphology, 207: 241-251.

Thomas, M. L. \& Simmons, L. W. (2007) Male crickets adjust the viability of their sperm in response to female mating status. The American Naturalist, 170(2): 190-195.

Thornhill, R. \& Alcock, J. (1983) The Evolution of Insect Mating Systems. Cambridge: Harvard University Press. 547 p.

Tomkins, J. L. \& Brown, G. S. (2004) Population density drives the local evolution of a threshold dimorphism. Nature, 431: 1099-1103.

Tomkins, J. L. \& Hazel, W. (2007) The status of the conditional evolutionarily stable strategy. Trends in Ecology and Evolution, 22(10): 522-528. 
Tomkins, J. L. \& Simmons, L. W. (2000) Sperm competition games played by dimorphic male beetles: fertilization gains with equal mating access. Proceedings of the Royal Society of London B: Biological Sciences, 267: 1547-1553.

Tomkins, J. L. \& Simmons, L. W. (2000) Sperm competition games played by dimorphic male beetles: fertilization gains with equal mating access. Proceedings of the Royal Society of London B: Biological Sciences, 267: 1547-1553.

Trivers, R. L. (1972) Parental Investment and Sexual Selection. In: Campbell, B. (Ed.) Sexual Selection and the Descent of Man. Chicago: Aldine Publishing Company, p.136-179.

Wedell, N. \& Cook, P. A. (1999) Butterflies tailor their ejaculate in response to sperm competition risk and intensity. Proceedings of the Royal Society of London B: Biological Sciences, 266: 1033-1039.

Wedell, N.; Gage, M. J. G. \& Parker, G. A. (2002) Sperm competition, male prudence and sperm-limited females. Trends in Ecology \& Evolution, 17(7): 313-320.

Westneat, D. F. \& Stewart, I. R. K. (2003) Extra-pair paternity in birds: causes, correlates, and conflict. Annual Review of Ecology, Evolution, and Systematics, 34: 365-396.

Wigby, S. \& Chapman, T. (2004) Sperm competition. Current Biology, 14(3): R100-R103.

Wigby, S. \& Chapman, T. (2005) Sex peptide causes mating costs in female Drosophila melanogaster. Current Biology, 15: 316-321.

Yamamura, N. \& Tsuji, N. (1989) Postcopulatory guarding strategy in a finite mating period. Theoretical Population Biology, 35: 36-50.

Young, J. Z. (1960) The statocysts of Octopus vulgaris. Proceedings of the Royal Society of London B: Biological Sciences, 152(946): 3-36.

Young, R. E.; Vecchione, M. \& Donovan, D.T. (1998) The evolution of coleoid cephalopods and their present biodiversity and ecology. South African Journal of Marine Science, 20: 393-420.

Zeh, J. A. \& Zeh, D. W. (2001) Reproductive mode and the genetic benefits of polyandry. Animal Behavior, 61: 1051-1063.

Zeidberg, L. D. (2009) First observations of "sneaker mating" in the California market squid, Doryteuthis opalescens, (Cephalopoda: Myopsida). Marine Biodiversity Records, 2(6): 1-4. 
